\title{
Notoginsenoside R1 ameliorates diabetic encephalopathy by activating the Nrf2 pathway and inhibiting NLRP3 inflammasome activation
}

\author{
Yadong Zhai ${ }^{1,2,3, *}$, Xiangbao Meng ${ }^{1,2,3, *}$, Yun Luo ${ }^{1,2,3}$, Yongmei Wu ${ }^{4}$, Tianyuan Ye ${ }^{1,2,3}$, \\ Ping Zhou ${ }^{1,2,3}$, Shilan Ding ${ }^{1,2,3}$, Min Wang ${ }^{5}$, Senbao Lu ${ }^{6}$, Lili Zhu ${ }^{7}$, Guibo Sun ${ }^{1,2,3}$ and \\ Xiaobo Sun ${ }^{1,2,3}$ \\ ${ }^{1}$ Beijing Key Laboratory of Innovative Drug Discovery of Traditional Chinese Medicine (Natural Medicine) and Translational \\ Medicine, Institute of Medicinal Plant Development, Peking Union Medical College and Chinese Academy of Medical Sciences, \\ Beijing, China \\ ${ }^{2}$ Key Laboratory of Bioactive Substances and Resource Utilization of Chinese Herbal Medicine, Ministry of Education, Beijing, \\ China \\ ${ }^{3}$ Key Laboratory of Efficacy Evaluation of Chinese Medicine Against Glycolipid Metabolic Disorders, State Administration of \\ Traditional Chinese Medicine, Beijing, China \\ ${ }^{4}$ Department of Pharmacology, Changchun University of Traditional Chinese Medicine, Changchun, China \\ ${ }^{5}$ College of Pharmacy, Harbin University of Commerce, Harbin, China \\ ${ }^{6}$ Department of Bioengineering, Santa Clara University, Santa Clara, California, USA \\ ${ }^{7}$ Guang'anmen Hospital, China Academy of Chinese Medical Sciences, Beijing, China \\ *These authors have contributed equally to this work \\ Correspondence to: Guibo Sun, email: sunguibo@126.com \\ Xiaobo Sun, email: sun_xiaobo163@163.com \\ Keywords: Notoginsenoside R1; diabetic encephalopathy; oxidative stress; Nrf2 pathway; NLRP3 inflammasome \\ Received: September 19,2017 Accepted: December 04, $2017 \quad$ Published: January 16, 2018 \\ Copyright: Zhai et al. This is an open-access article distributed under the terms of the Creative Commons Attribution License 3.0 \\ (CC BY 3.0), which permits unrestricted use, distribution, and reproduction in any medium, provided the original author and source \\ are credited.
}

\section{ABSTRACT}

Numerous researches supported that oxidative stress and inflammation play important roles in the development of diabetic encephalopathy (DEP). Notoginsenoside R1 (NGR1), one major component of Panax notoginseng, is believed to have anti-oxidative, anti-inflammatory and neuroprotective properties. However, its neuroprotective effects against DEP and underlying mechanisms are still unknown. In this study, db/db mice as well as high-glucose (HG)-treated HT22 hippocampal neurons were used as in vivo and in vitro models to estimate NGR1 neuroprotection. NGR1 administration for 10 weeks could ameliorate cognitive dysfunction, depression-like behaviors, insulin resistance, hyperinsulinemia, dyslipidemia, and inflammation in $\mathrm{db} / \mathrm{db}$ mice. NGR1 markedly decreased the oxidative stress induced by hyperglycemia in hippocampal neurons. NGR1 significantly activated the protein kinase B (Akt)/nuclear factor-erythroid 2-related factor2 (Nrf2) pathway, and inhibited NLRP3 inflammasome activation in hippocampal neurons, which might be essential for the neuroprotective effects of NGR1. Further supporting these results, we observed that pretreatment with the phosphatidylinositol 3-kinase inhibitor LY294002 abolished NGR1-mediated neuroprotective effects against oxidative stress and NLRP3 inflammasome activation in HG-treated HT22 hippocampal neurons. In conclusion, the present study demonstrates the neuroprotective effects of NGR1 on DEP by activating the Akt/Nrf2 pathway and inhibiting NLRP3 inflammasome 


\section{activation. This study also provides a novel strategy for the application of NGR1 as a therapeutic agent for patients with DEP.}

\section{INTRODUCTION}

Type 2 diabetes mellitus (T2DM), characterized by hyperglycemia due to insulin resistance, impairs hippocampal structure and function. Recent epidemiological findings have indicated that diabetes mellitus (DM) is an independent risk factor of the development of cognitive dysfunction [1]. Patients with DM have a higher risk of developing Alzheimer's disease (AD) and vascular dementia in the process of aging than non-DM control subjects [2, 3]. In addition, converging evidences have indentified that an augmented risk of neuropsychiatric disorders in DM $[4,5]$. This complex complication of diabetes is recognized as diabetic encephalopathy (DEP) [6,7], and its underlying mechanism is unclear. Impaired insulin signaling, advanced glycation end-product, neuronal apoptosis, vascular dysfunction, metabolic abnormalities, oxidative stress, endoplasmic reticulum stress, and inflammation were all involved in the development of DEP [7, 8].

Chronic metabolic inflammation in the hippocampus accelerates the development of neurodegenerative diseases. Interleukine-1 $\beta$ (IL-1 $\beta$ ), an important pro-inflammatory cytokine, is involved in the development of diseases related to the central nervous system (CNS) [9]. The IL-1 $\beta$ maturation is mediated by the nucleotide binding and oligomerization domain-like (Nod) receptor family pyrin domain-containing 3 (NLRP3) inflammasome, which consists of a recognition receptor (NLRP3), an apoptosis-associated speck-like protein containing a card (ASC) and an effector molecule (caspase-1). The inhibition of NLRP3 inflammasome activation can ameliorate $\mathrm{AD}$ and neuropsychiatric disorders [10-12]. NLRP3 inflammasome is also implicated in diabetic complications. And inhibiting NLRP3 inflammasome activation can alleviate the complications of DM [13]. Moreover, hippocampal neurons treated with high glucose (HG) can activate NLRP3 inflammasome, which supported that NLRP3 inflammasome plays a vital role in the development of DEP [14].

Signaling intermediates that activate NLRP3 inflammasome remain unclear. Recent investigations showed that thioredoxin-interacting protein (TXNIP) is an important intermediate that binds to and activates NLRP3 in a mechanism dependent on reactive oxygen species (ROS) [15]. Heme oxygenase-1 (HO-1), an endogenous cytoprotective enzyme produced in response to oxidative stress, and its gene transcriptional activation are regulated by nuclear factor-erythroid 2-related factor2 (Nrf2) [16]. HO-1 exhibits potential properties of clearing ROS and anti-oxidative stress. Activating the hippocampal Nrf2/ HO-1 pathway can improve learning and memory decline induced by obesity [17]. Nrf2 nuclear translocation is activated by the phosphatidylinositol 3-kinase /protein kinase B (PI3K/Akt) pathway [18]. Moreover, activating this pathway can lead to the reduction of TXNIP expression [19]. Therefore, activating the PI3K/ Akt pathway and increasing HO-1 expres.+sion may provide a novel target to inhibit ROS/TXNIP/NLRP3 inflammasome.

Saponins from Panax notoginseng can protect hippocampal neurons and improve spatial cognitive disorders in diabetic mice [20]. Notoginsenoside R1 (NGR1, its molecular structure is shown in Figure 1A), which is a major component and novel saponin isolated from P. notoginseng, exhibits anti-oxidative, anti-inflammatory, and anti-apoptotic properties [21]. In our previous study, NGR1 elicits neuroprotective effects against cerebral ischemia/reperfusion injury by activating the $\mathrm{Akt} / \mathrm{Nrf2} / \mathrm{HO}-1$ pathway in vivo and in vitro [16]. NGR1 also attenuates $A \beta_{25-35}$ induced injury in PC12 neuronal cells by suppressing oxidative stress, and inhibiting stress-activated mitogen-activated protein kinase (MAPK) signaling pathways [22]. Our previous research indentified that NGR1 exerts cardioprotective abilities against ischemia/reperfusion damage by inhibiting oxidative stress, endoplasmic reticulum stress, and cell apoptosis [23]. NGR1 also can improve the learning performance of APP/PS1 mice by increasing insulin degrading enzyme activity and inhibiting A $\beta$ accumulation [24]. Moreover, NGR1 can ameliorate diabetic nephropathy in diabetic rats by activating PI3K/Akt signaling pathway, increasing nephrin and podocin expressions, decreasing desmin expression, and inhibiting inflammation and apoptosis of podocytes [25]. These studies emphasize the potential function of NGR1 in cerebrovascular diseases, neurodegenerative disorders, and diabetic complications. However, whether NGR1 can ameliorate DEP or whether its ameliorative effects are related to the inhibition of oxidative stress or NLRP3 inflammasome activation remains to be determined.

In this study, we investigated the neuroprotective effects and the underlying mechanisms of NGR1 on HG-induced HT22 hippocampal neurons injury, and oxidative stress $[26,27]$ and DEP in $\mathrm{db} / \mathrm{db}$ mice, which display T2DM characteristic, including hyperglycemia, obesity, hyperinsulinemia, and insulin resistance and show neurobehavioral deficits, including cognitive dysfunction, depression, and anxiety [4, 5, 28, 29]. In vivo and in vitro analyses indicated that NGR1 could inhibit hyperglycemia induced oxidative stress and NLRP3 inflammasome activation through activating the Akt/Nrf2/HO-1 pathway in hippocampal neurons. Our findings demonstrated that NGR1 could be applied to treat and prevent DEP. 


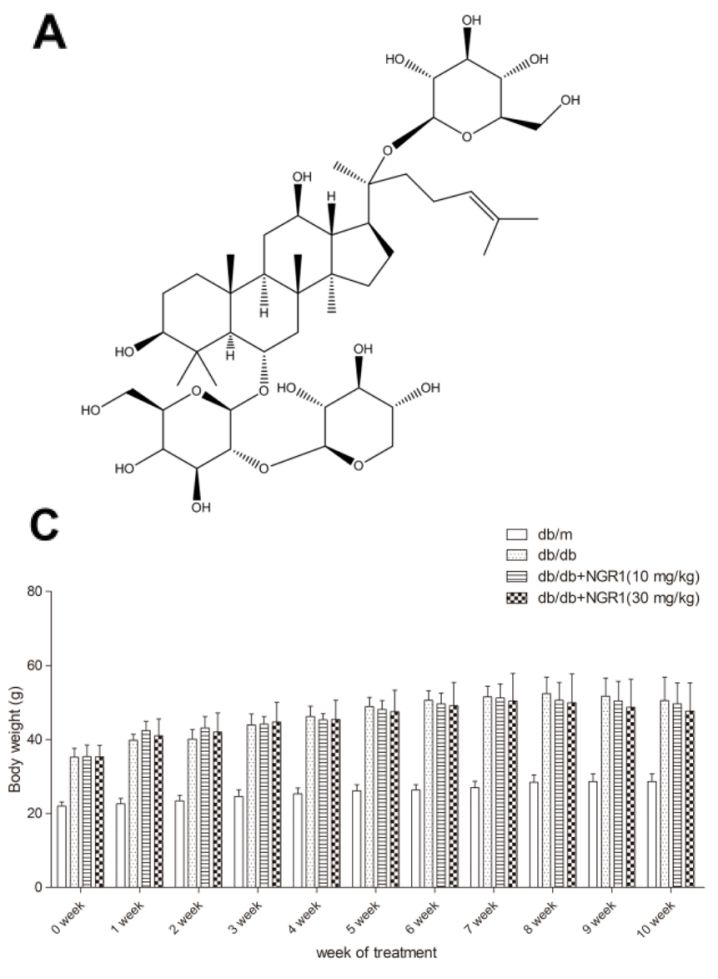

B
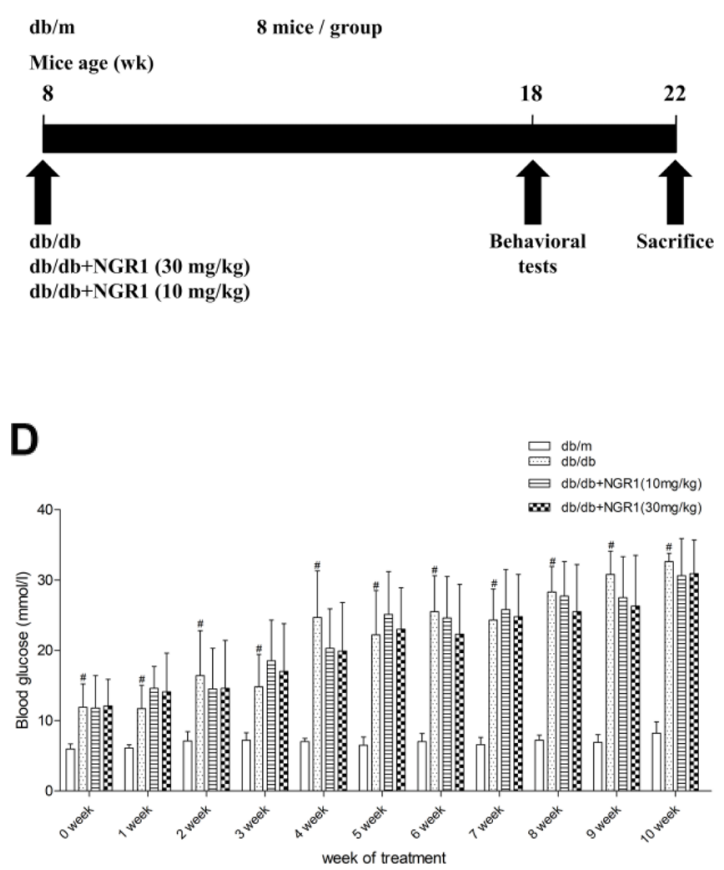

E

\section{$\mathbf{F}$}

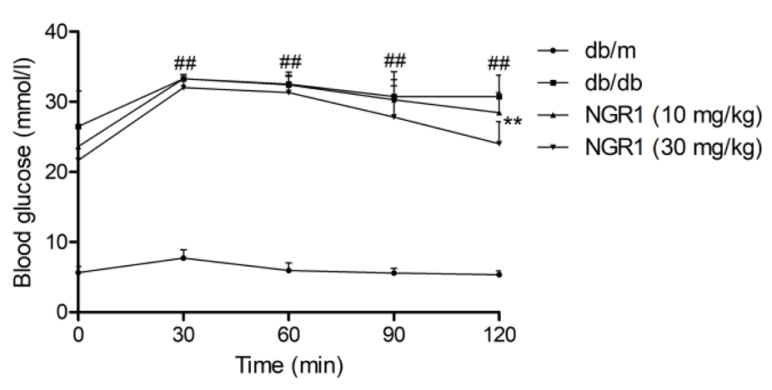

G

H
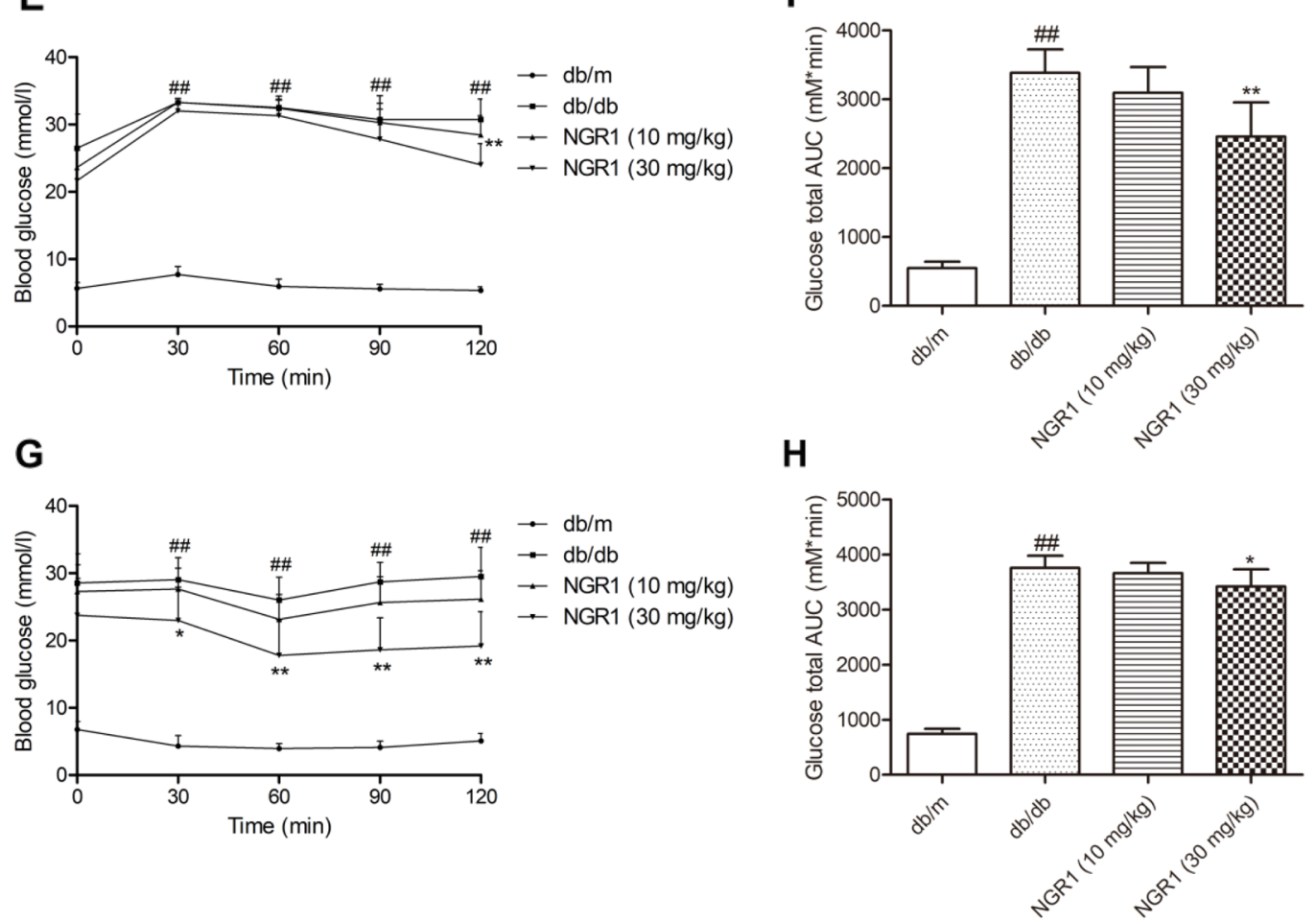

Figure 1: NGR1 improves insulin resistance in db/db mice. (A) Chemical structure of NGR1; molecular weight is 933; molecular formula is $\mathrm{C}_{47} \mathrm{H}_{80} \mathrm{O}_{18}$. (B) Schematic diagram showing the timeline scheme of the animal experiments in vivo. (C) Body weights of mice in each group during 10 weeks of treatment. (D) Blood glucose level of mice in each group during 10 weeks of treatment. (E) Curve of blood glucose levels in OGTTs. (F) Glucose total AUC in OGTTs. (G) Curve of blood glucose levels in ITTs. (H) Glucose total AUC in ITTs. All data are represented as means $\pm \mathrm{SD}$ for 8 mice in each group. ${ }^{\# \prime} P<0.01$, compared with the $\mathrm{db} / \mathrm{m}$-group; ${ }^{* *} p<0.01,{ }^{*} p<0.05$, compared with the $\mathrm{db} / \mathrm{db}$-group. 


\section{RESULTS}

\section{Effect of NGR1 on body weight and fasting blood glucose level in $\mathrm{db} / \mathrm{db}$ mice}

In Figure 1C and 1D, body weight and fasting blood glucose level significantly increased in the diabetic $\mathrm{db} / \mathrm{db}$ mice compared with those in the non-diabetic $\mathrm{db} / \mathrm{m}$ mice. No obvious differences in body weight and blood glucose level were found between the mice in the NGR1 (10 or $30 \mathrm{mg} / \mathrm{kg}$ ) group and the mice in the model group until 10 weeks of treatment.

\section{NGR1 improved glucose tolerance and insulin sensitivity in $\mathbf{d b} / \mathbf{d b}$ mice}

As shown in Figure 1E, blood glucose level continuously increased at all time points during the oral glucose tolerance tests (OGTTs) in $\mathrm{db} / \mathrm{db}$ mice compared with the $\mathrm{db} / \mathrm{m}$ mice $(P<0.01)$. Glucose total area under the curve (AUC) of the model group was obviously increased compared with the control group $(P<0.01)$ (Figure 1F). Interestingly, administration of NGR1 (30 $\mathrm{mg} / \mathrm{kg}$ ) significantly decreased the blood glucose level at $120 \mathrm{~min}(P<0.01)$ and greatly reduced the glucose total AUC compared with the model group $(P<0.05)$. In addition, treatment with NGR1 $(30 \mathrm{mg} / \mathrm{kg})$ showed an obvious difference in the rapid removal of blood glucose compared with the model group in insulin tolerance tests (ITTs) $(P<0.05, P<0.01)$ (Figure $1 \mathrm{G})$. As shown in Figure $1 \mathrm{H}$, glucose total AUC of the NGR1 $(30 \mathrm{mg} / \mathrm{kg})$ group in ITTs was significantly decreased compared with the model group $(P<0.01)$.

\section{NGR1 attenuates depression-like behaviors and memory impairment in $\mathrm{db} / \mathrm{db}$ mice}

Tail suspension test (TST) and forced swim test (FST) were regarded as classical experiments to evaluate depression. In the TST and FST, obvious differences were found among mice in the $\mathrm{db} / \mathrm{db}$ and $\mathrm{db} / \mathrm{m}$ groups. As shown in Figure $2 \mathrm{~A}$ and $2 \mathrm{~B}, \mathrm{db} / \mathrm{db}$ mice showed increased immobility time in TST and FST $(P<0.01)$, which were considered as more depressive than the wild type. Interestingly, NGR1 (10 and $30 \mathrm{mg} / \mathrm{kg}$ ) treatment observably decreased the immobility time in TST and FST of $\mathrm{db} / \mathrm{db}$ mice $(P<0.01)$. These data confirmed that NGR1 may improve depression-like behaviors in $\mathrm{db} / \mathrm{db}$ mice.

As shown in Figure 2C, in the visible-platform test, the escape latency was similar in each group, which indicated no obvious differences in motivation and vision among all groups. In the spatial hidden-platform test (Figure 2D), the escape latency was shorter in the $\mathrm{db} / \mathrm{m}$ group than in the model group in days 2 and $3(P<0.05)$. Interestingly, $\mathrm{db} / \mathrm{db}$ mice treated with NGR1 $(30 \mathrm{mg} / \mathrm{kg})$ for 10 weeks showed remarkably reduced escape latency at day 3 compared with those in the model group. In the probe test (Figure 2E), a putative measurement of spatial learning and memory retention, $\mathrm{db} / \mathrm{db}$ mice displayed less preference for the target quadrant. As shown in Figure $2 \mathrm{~F}$ and $2 \mathrm{G}$, the number of target crossings and the percentage of total time in the target quadrant were obviously decreased in $\mathrm{db} / \mathrm{db}$ mice compared with those in $\mathrm{db} / \mathrm{m}$ mice. By contrast, $\mathrm{db} / \mathrm{db}$ mice treated with NGR1 $(30 \mathrm{mg} / \mathrm{kg}$ ) showed more preference for the target quadrant and higher frequency of crossing the platform compared with vehicle-treated $\mathrm{db} / \mathrm{db}$ mice $(P<0.05)$. These data indicated that NGR1 may ameliorate memory disorder in $\mathrm{db} / \mathrm{db}$ mice.

\section{NGR1 improves hyperinsulinemia and dyslipidemia in $\mathbf{~ d b / d b}$ mice}

As shown in Figure 3A, 3B, and 3C, total cholesterol (TC), triglyceride (TG), and low-density lipoprotein cholesterol (LDL-C) levels in plasma were significantly increased in $\mathrm{db} / \mathrm{db}$ mice compared with $\mathrm{db} / \mathrm{m}$ mice; however, treatment with NGR1 $(30 \mathrm{mg} / \mathrm{kg})$ for 10 weeks observably decreased TC, TG, and LDL-C levels in $\mathrm{db} / \mathrm{db}$ mice. As shown in Figure 3D, the level of highdensity lipoprotein cholesterol (HDL-C) in plasma of db/ $\mathrm{db}$ mice was higher than that in $\mathrm{db} / \mathrm{m}$ mice. However, NGR1 treatment could not affect the HDL-C level in db/ $\mathrm{db}$ mice. Moreover, as shown in Figure 3E, diabetic db/ $\mathrm{db}$ mice showed a markedly higher level of plasma insulin than $\mathrm{db} / \mathrm{m}$ mice. Interestingly, treatment with NGR1 $(30 \mathrm{mg} / \mathrm{kg})$ for 10 weeks exhibited effects in reducing plasma insulin levels in $\mathrm{db} / \mathrm{db}$ mice. These data indicated that NGR1 can improve lipid and insulin disorders in plasma of $\mathrm{db} / \mathrm{db}$ mice.

\section{NGR1 reduces increased plasma levels of inflammatory factors in $\mathrm{db} / \mathrm{db}$ mice}

The diabetic $\mathrm{db} / \mathrm{db}$ mice showed higher plasma IL$1 \beta$, interleukine-6 (IL-6), tumor necrosis factor- $\alpha$ (TNF- $\alpha$ ), and monocyte chemoattractant protein-1 (MCP-1) levels than $\mathrm{db} / \mathrm{m}$ mice $(P<0.01)$ (Figure $3 \mathrm{~F}, 3 \mathrm{G}, 3 \mathrm{H}$, and $3 \mathrm{I}$ ). Treatment with NGR1 (10 or $30 \mathrm{mg} / \mathrm{kg}$ ) for 10 weeks lowered plasma IL-1 $\beta$, TNF- $\alpha$, and MCP-1 levels than vehicle-treated $\mathrm{db} / \mathrm{db}$ mice $(P<0.01, P<0.05)$. Moreover, NGR1 $(30 \mathrm{mg} / \mathrm{kg})$ treatment significantly reduced the plasma IL-6 level in $\mathrm{db} / \mathrm{db}$ mice compared with those in the model group $(P<0.01)$.

\section{H\&E, Nissl's, and TUNEL staining}

As shown in Figure 4A, H\&E staining showed the round and pale stained nuclei of neurons that were predominantly seen in the $\mathrm{db} / \mathrm{m}$ group. In diabetic $\mathrm{db} / \mathrm{db}$ mice, neurons showing pyknotic nuclei were seen in 
the CA1 regions of the hippocampus. Interestingly, administration of NGR1 (10 or $30 \mathrm{mg} / \mathrm{kg}$ ) reduced the pyknotic nuclei in the CA1 regions of the hippocampus in $\mathrm{db} / \mathrm{db}$ mice. As shown in Figure 4B, many neurons had shrunk phenotype and were irregularly scattered in the hippocampal CA1 region of $\mathrm{db} / \mathrm{db}$ mice. Most neurons exhibited weak staining, which indicated that neurons were diffusely deteriorated and lots of Nissl bodies lost in these neurons. In contrast to the mice in $\mathrm{db} / \mathrm{db}$ group, the mice in $\mathrm{db} / \mathrm{m}$ group exhibited strong staining and
A

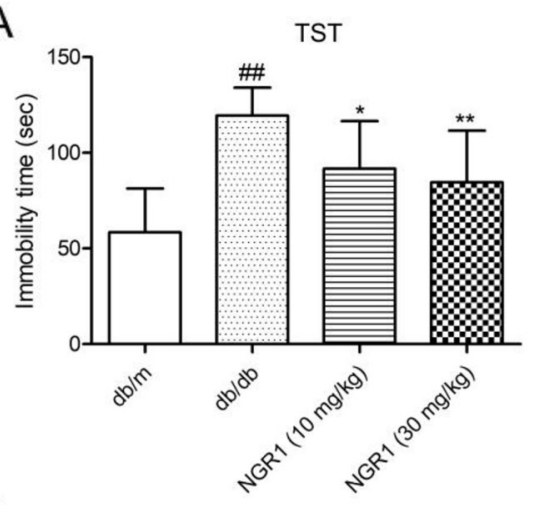

C

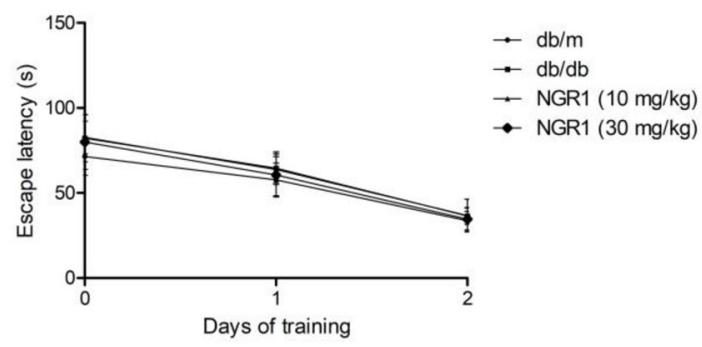

B
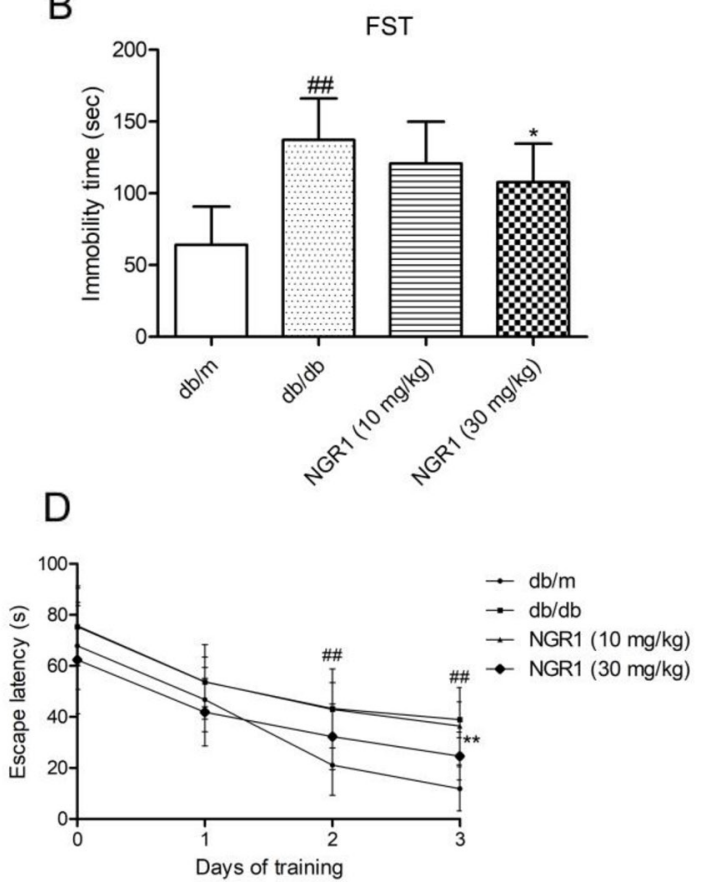

$\mathrm{E}$
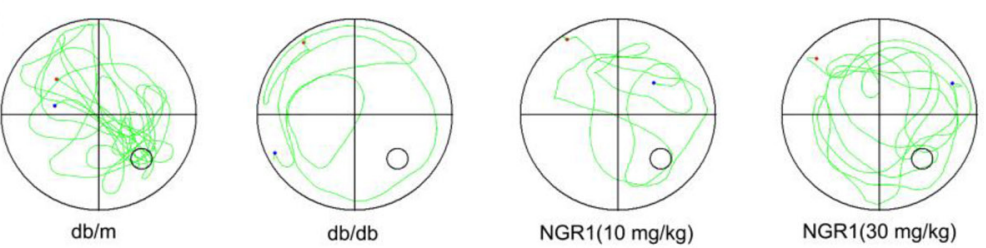

$\mathrm{F}$

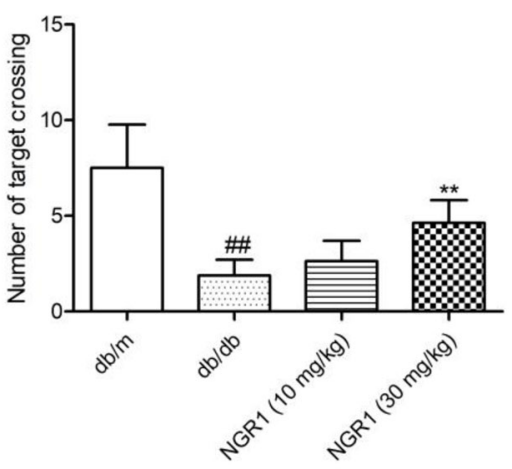

G

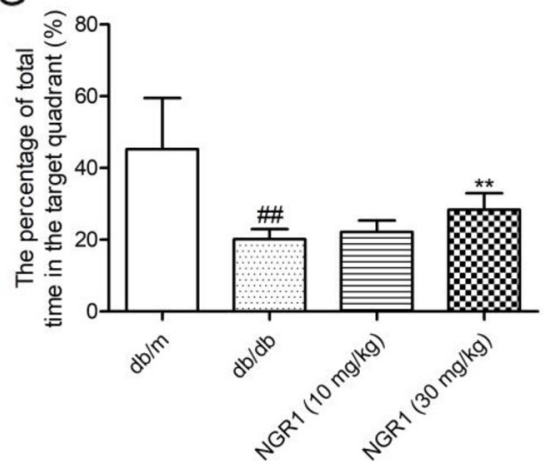

Figure 2: NGR1 attenuates depression-like behaviors and memory impairment in db/db mice. In the Morris water maze (MWM) test, day 0 means performance on the first trial, and subsequent points indicate average of all daily trials. (A) Immobility time in TST. (B) Immobility time in FST. (C) Escape latency of the two-day visible-platform test. (D) Escape latency of the three-day hiddenplatform test. (E) Representative swim paths during the probe test. (F) Percentage of total time spent in target quadrant in the probe trial. (G) Number of target crossings in the probe trial. Values are represented as means \pm SD for 8 mice in each group. ${ }^{\#} P<0.01$, compared with the db/m-group; ${ }^{* *} p<0.01,{ }^{*} p<0.05$, compared with the $\mathrm{db} / \mathrm{db}$-group. 
possessed neurons arranged regularly in the hippocampal CA1 region. TUNEL staining was used to detect cell apoptosis. Figure 4C showed that there were many positive TUNEL cells in the hippocampal CA1 region of $\mathrm{db} / \mathrm{db}$ mice, while there were almost no detectable positive TUNEL cells in $\mathrm{db} / \mathrm{m}$ mice. NGR 1 treatment decreased the cell apoptosis in the hippocampal CA1 region of $\mathrm{db} / \mathrm{db}$ mice. The results of $H \& E$, Nissl, and TUNEL staining indicated that NGR1 ameliorates the hippocampal damage in $\mathrm{db} / \mathrm{db}$ mice.

\section{NGR1 inhibits hippocampal NLRP3 inflammasome activation in $\mathrm{db} / \mathrm{db}$ mice}

Compared with the $\mathrm{db} / \mathrm{m}$ mice, the active IL- $1 \beta$ protein expression level was significantly increased in the hippocampus of $\mathrm{db} / \mathrm{db}$ mice, which suggested activation of NLRP3 inflammasome in the hippocampus (Figure 4D). We detected caspase-1 activity (Figure $4 \mathrm{E}$ ) and evaluated protein expression levels of NLRP3 and ASC in the hippocampus (Figure 4D). As expected, caspase-1 activity and NLRP3 and ASC expression levels in the hippocampus were significantly increased in $\mathrm{db} / \mathrm{db}$ mice compared with $\mathrm{db} / \mathrm{m}$ mice $(P<0.01)$. Interestingly, $\mathrm{db} / \mathrm{db}$ mice treated with NGR1 (30 mg/kg) exhibited a significant decrease in caspase- 1 activity $(P<0.05)$ as well as NLRP3, ASC, and IL-1 $\beta$ expression levels $(P<0.05)$ in the hippocampus compared with the $\mathrm{db} / \mathrm{db}$ group. Administration of NGR1 could decrease NLRP3 inflammasome activation and IL-1 $\beta$ expression level to improve the hippocampal inflammation response in $\mathrm{db} /$ $\mathrm{db}$ mice.

Activated microglia cells are main source of central nervous system inflammatory cytokines
A

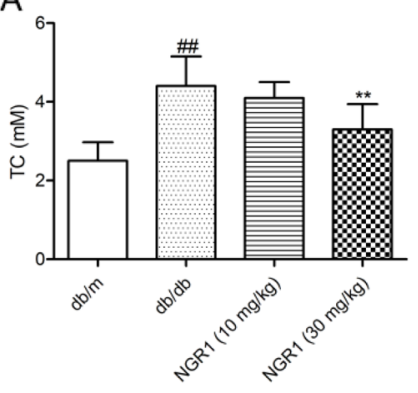

D

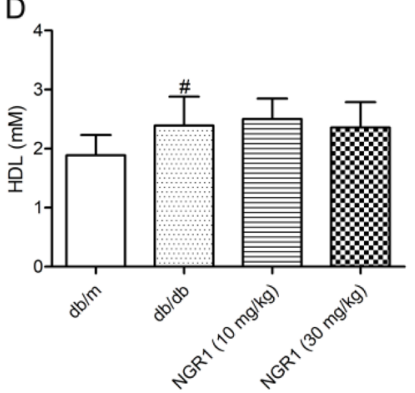

G

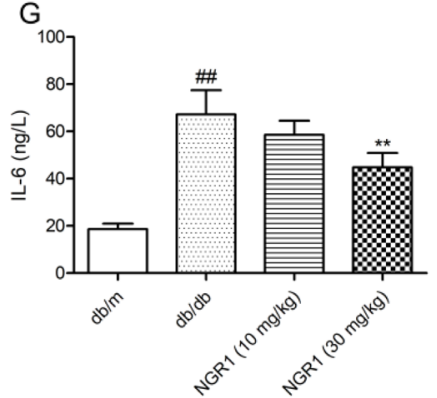

B

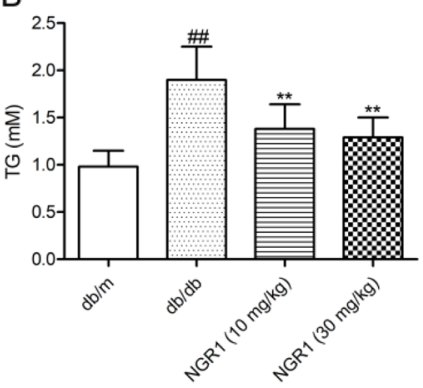

$\mathrm{E}$

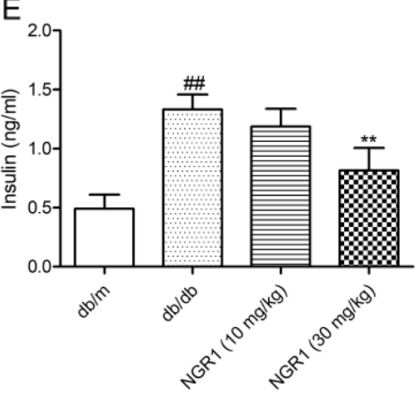

$\mathrm{H}$

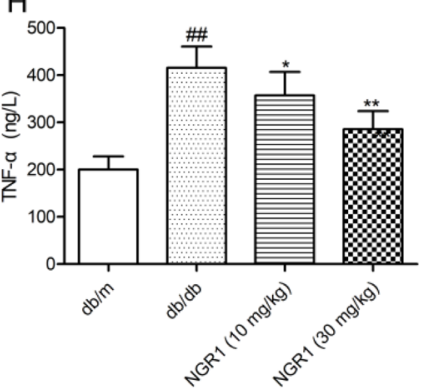

C

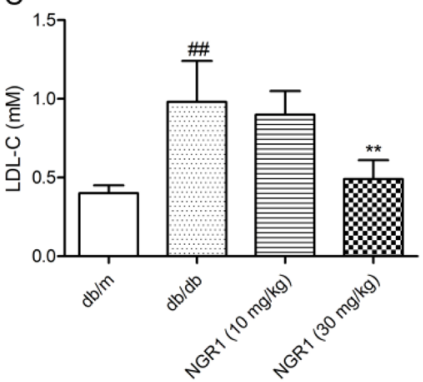

$\mathrm{F}$

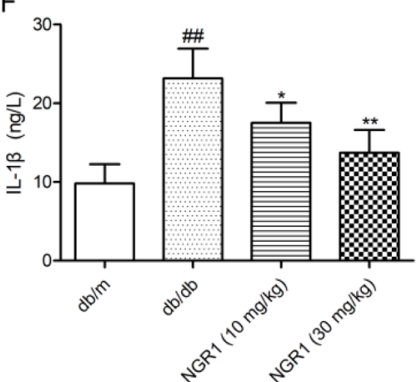

1

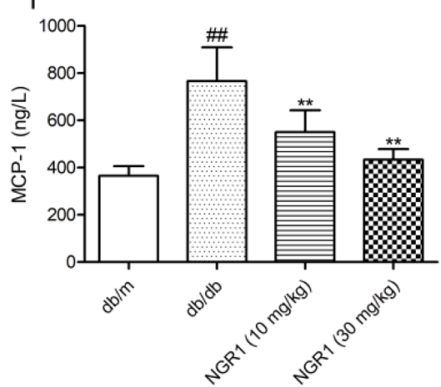

Figure 3: NGR1 influences lipids, insulin, and cytokines in plasma of db/db mice. (A) Levels of TC in plasma samples of mice after 10 weeks of treatment. (B) Levels of TG in plasma samples of mice after 10 weeks of treatment. (C) Levels of LDL-C in plasma samples of mice after 10 weeks of treatment. (D) Levels of HDL-C in plasma samples of mice after 10 weeks of treatment. (E) Levels of insulin in plasma samples of mice after 10 weeks of treatment. (F) Levels of IL-1 $\beta$ in plasma samples of mice after 10 weeks of treatment. (G) Levels of IL-6 in plasma samples of mice after 10 weeks of treatment. (H) Levels of TNF- $\alpha$ in plasma samples of mice after 10 weeks of treatment. (I) Levels of MCP-1 in plasma samples of mice after 10 weeks of treatment. Values are represented as means \pm SD for 8 mice in each group. ${ }^{\#} P<0.01,{ }^{\#} P<0.05$, compared with the db/m-group; ${ }^{* *} P<0.01,{ }^{*} P<0.05$, compared with the db/db-group. 
$[11,30]$. As described in Figure 4F, the expression microglia cell marker CD11b protein was significantly increased in the hippocampus of $\mathrm{db} /$ $\mathrm{db}$ mice as compared to $\mathrm{db} / \mathrm{m}$ mice $(P<0.01)$.

A

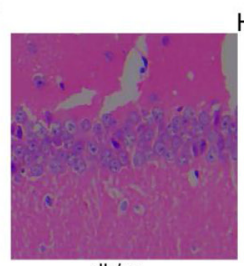

$\mathrm{db} / \mathrm{m}$
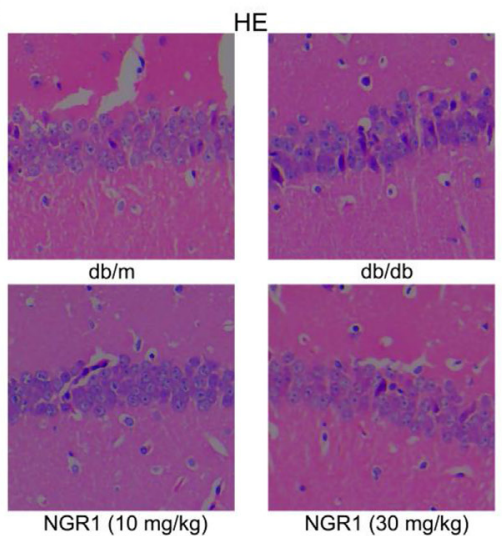

C

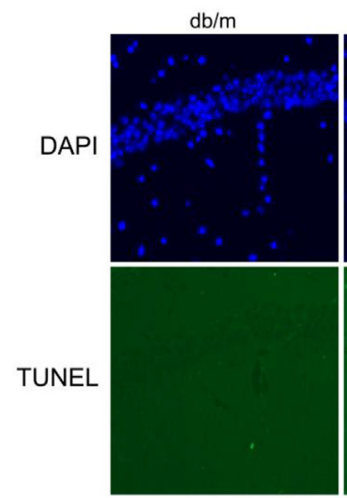

D

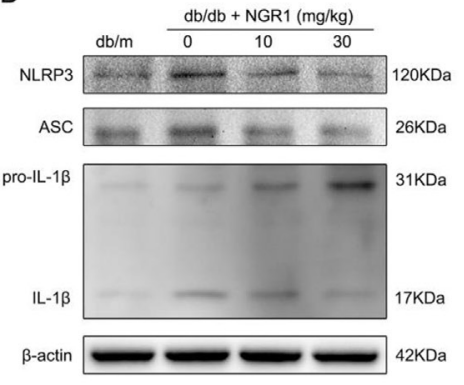

$\mathrm{F}$
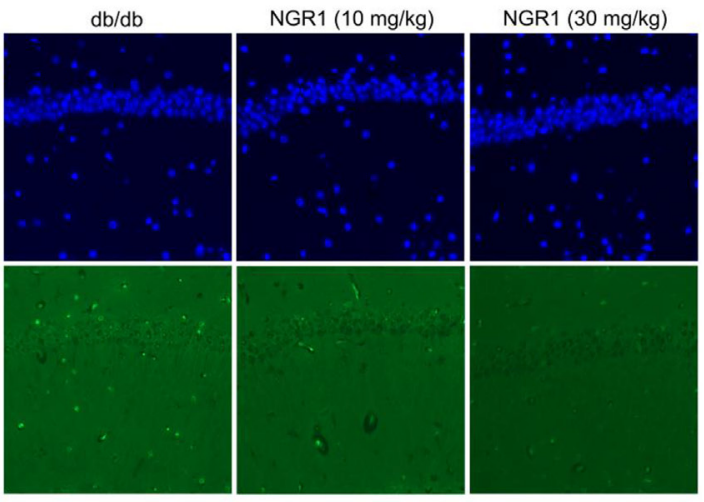

E

NGR1 $(30 \mathrm{mg} / \mathrm{kg})$
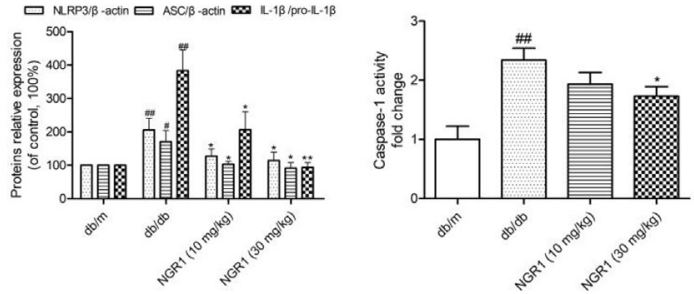

NGR1 $(30 \mathrm{mg} / \mathrm{kg})$ treatment significantly reduced hippocampal CD11b protein expression in $\mathrm{db} / \mathrm{db}$ mice $(P<0.05)$, which suggested that NGR1 can ameliorate neuroinflammation.

B

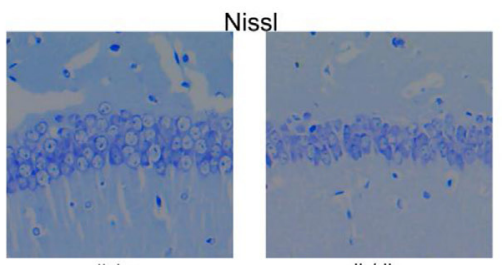

$\mathrm{db} / \mathrm{m}$

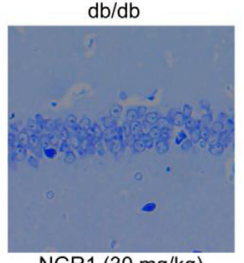

NGR1 $(30 \mathrm{mg} / \mathrm{kg})$

NGR1 (10 mg/kg)
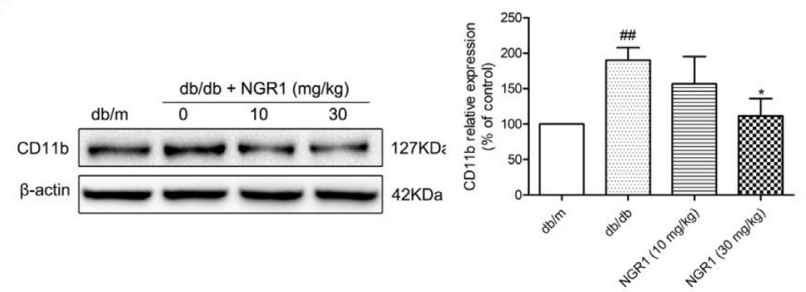

Figure 4: NGR1 exerts neuroprotective effects by inhibiting NLRP3 inflammasome activation in hippocampus of db/ db mice. (A) H\&E staining in the hippocampal CA1 region for each group. (B) Nissl's staining in the hippocampal CA1 region for each group. (C) TUNEL staining in the hippocampal CA1 region for each group. (D) Representative protein bands and Western blot analysis of NLRP3, ASC and IL-1 $($ P31 and P17) in the hippocampus of each group. (E) Caspase-1 activity in the hippocampus of each group. (F) Representative protein bands and Western blot analysis of CD11b in hippocampus of each group. All data are represented as means \pm SD for 3 mice in each group. ${ }^{\# \#} P<0.01,{ }^{\#} P<0.05$, compared with the $\mathrm{db} / \mathrm{m}$-group; ${ }^{* *} p<0.01,{ }^{*} p<0.05$, compared with the db/db-group. 


\section{NGR1 reduces hippocampal oxidative stress by activating the Akt/Nrf2/HO-1 pathway in $\mathrm{db} / \mathrm{db}$ mice}

To determine whether oxidative stress was involved in hippocampal NLRP3 inflammasome activation in $\mathrm{db} / \mathrm{db}$ mice, we detected hippocampal oxidative stress markers, including superoxide dismutase (SOD), malondialdehyde (MDA), and protein carbonyl. As shown in Figure 5A, 5B, and $5 \mathrm{C}$, SOD activity significantly decreased, whereas MDA and protein carbonyl levels were remarkably increased in the hippocampus of $\mathrm{db} / \mathrm{db}$ mice compared with the $\mathrm{db} / \mathrm{m}$ group $(P<0.01)$. Moreover, NGR1 treatment could enhance anti-oxidant enzyme SOD activity and lower MDA, and protein carbonyl levels in the hippocampus of $\mathrm{db} / \mathrm{db}$ mice $(P<0.05, P<0.01)$. These results indicated that NGR1 treatment could suppress hippocampal oxidative stress in $\mathrm{db} / \mathrm{db}$ mice, which may contribute to the inhibition of NLRP3 inflammasome activation.

Given that HO-1 exerts anti-inflammatory response and anti-oxidative stress properties, we examined hippocampal HO-1 expression. As shown in Figure $5 \mathrm{D}, \mathrm{db} / \mathrm{db}$ mice had lower HO-1 expression level than $\mathrm{db} / \mathrm{m}$ mice $(P<0.01)$, which indicated that diabetes could suppress hippocampal HO-1 expression. It is well known that HO-1 expression is activated through nuclear transcription factor Nrf2, therefore, we further analyzed the hippocampal Nrf2 expression level. As expected, the Nrf2 expression level was lower in $\mathrm{db} / \mathrm{db}$ mice than in $\mathrm{db} / \mathrm{m}$ mice. Moreover, activation of the PI3K/Akt signal transduction pathway could promote Nrf2 nuclear translocation; thus, we detected the hippocampal Akt and phospho-Akt (p-Akt) expression. Similar to aprevious report [31], our study supported that expression levels of phosphorylated Akt were lower in diabetic $\mathrm{db} / \mathrm{db}$ mice than in non-diabetic $\mathrm{db} / \mathrm{m}$ mice $(P<0.01)$. This finding suggested that diabetes could also inhibit Akt phosphorylation in the hippocampus.

TXNIP, one of the important factors for NLRP3 inflammasome activation, can be activated by oxidative stress $[15,19]$. As shown in Figure 5D, TXNIP expression levels were obviously increased in $\mathrm{db} / \mathrm{db}$ mice $(P<0.01)$ compared with the $\mathrm{db} / \mathrm{m}$ group. Interestingly, compared with the model group, treatment with NGR1 observably increased hippocampal phospho-Akt, Nrf2, and HO-1 expression levels and decreased TXNIP expression levels in $\mathrm{db} / \mathrm{db}$ mice $(P<0.05)$. These results suggested that 10 weeks of NGR1 treatment could significantly activate the Akt/Nrf2 pathway and promote HO-1 expression, which result in a decrease in oxidative stress and NLRP3 inflammasome activation in the hippocampus of $\mathrm{db} / \mathrm{db}$ mice.

\section{HG-induced HT22 hippocampal neurons injury, NLRP3 inflammasome activation and ROS production}

To investigate the roles of NGR1 in ameliorating DEP mechanistically, we established an in vivo model with HT22 hippocampal neurons exposed to HG (total $50 \mathrm{mM}$ ), as previously reported [26]. HT22 hippocampal neurons
A
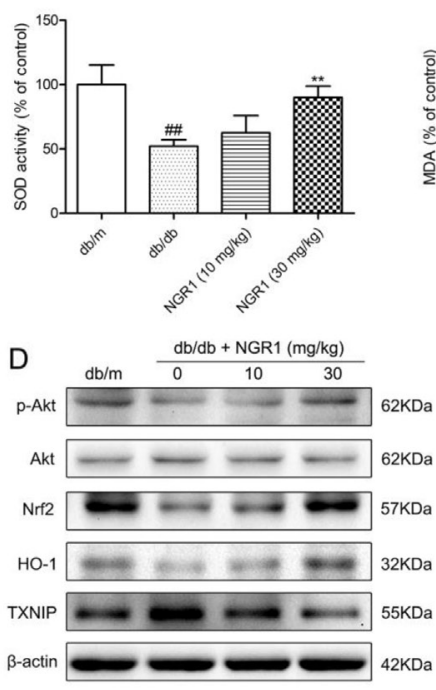

B
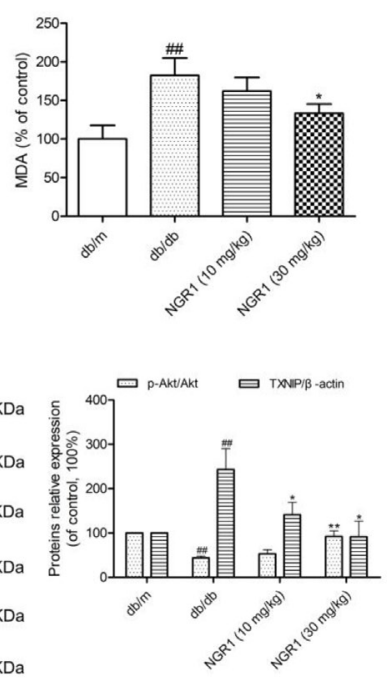

$\mathrm{C}$
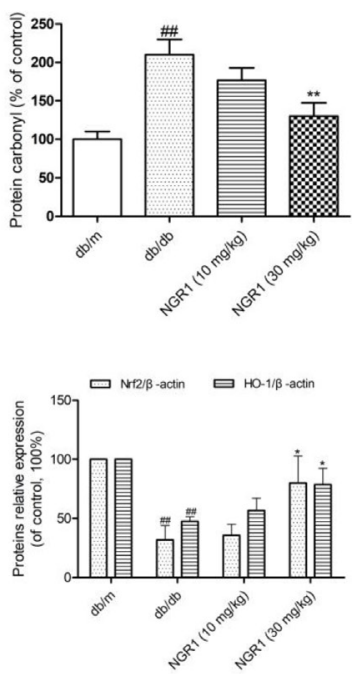

Figure 5: NGR1 inhibits oxidative stress by up-regulating the Akt/Nrf2/HO-1 pathway in the hippocampus of db/db mice. (A) SOD activity in the hippocampus of each group. (B) MDA levels in the hippocampus of each group. (C) Protein carbonyl levels in the hippocampus of each group. (D) Representative protein bands and Western blot analysis of Akt, p-Akt, Nrf2, HO-1, and TXNIP in the hippocampus of each group. Values are represented as means $\pm \mathrm{SD}$ for 3 mice in each group. ${ }^{\# \#} P<0.01$, compared with the db/m-group; ${ }^{* *}$ $P<0.01,{ }^{*} P<0.05$, compared with the db/db-group. 
were exposed to HG for 12, 24, and $36 \mathrm{~h}$. Cell viability were detected by MTT assay. The percentage of cell viability in each group was calculated relative to control. As shown in Figure 6A, 24 h HG treatment caused a decrease in cell viability approximately by $12 \%$. Moreover, cell viability at $36 \mathrm{~h}$ after HG treatment was around $77 \%$. We also detected caspase- 3 , and caspase- 1 activities and IL-1 $\beta$ levels at 12,24 , and $36 \mathrm{~h}$ after incubation with HG. Interestingly, caspase-3, and caspase-1 activities and IL-1 $\beta$ level were higher at $36 \mathrm{~h}$ than at other time points (Figure 6B, 6C, and 6D). The intracellular ROS level was evaluated by detecting DCFH-DA fluorescence. As shown in Figure 6E, there was a significant increase in ROS production in HT22 hippocampal neurons at $36 \mathrm{~h}$ after $\mathrm{HG}$ treatment. On the basis of these results, incubation with $\mathrm{HG}$ for $36 \mathrm{~h}$ was selected as an optimal condition for the following experiments.

\section{NGR1 protects HT22 hippocampus neurons from hyperglycemia induced cell injury and intracellular oxidative stress}

The potential neuroprotective effects of NGR1 on HT22 cells against HG-induced injury were evaluated by measuring cell viability, caspase- 3 activity, and lactate dehydrogenase (LDH) release. Although high concentrations of NGR1 $(40 \mu \mathrm{M})$ showed certain cytotoxicity in HT22 cells that underwent incubation for $36 \mathrm{~h}$, no obvious difference in cell viability was observed among the groups at low concentrations $(5,10$, and $20 \mu \mathrm{M})$ and the control group $(P>0.05)$ (Figure 7A). $\mathrm{N}$-acetyl-L-cysteine (NAC, $10 \mathrm{mM}$ ), a classical antioxidant, was used as a positive control [32]. As shown in Figure 7B, HT22 cells subjected to HG (50 mM) for $36 \mathrm{~h}$ showed significantly decreased cell viability $(P<0.01)$, and incubation with NGR1 obviously inhibited this decrease in a concentration-dependent manner $(5,10$, and $20 \mu \mathrm{M})(P<0.05, P<0.01)$. Moreover, HG treatment observably increased caspase-3 activity and LDH leakage in HT22 cells $(P<0.01)$ (Figure 7C, and 7E). And incubation with NGR1 $(20 \mu \mathrm{M})$ observably decreased the caspase-3 activity and LDH leakage compared with the model group $(P<0.01)$. No obvious difference in cell viability, caspase-3 activity and LDH leakage was observed between the group treated with NGR1 $(20 \mu \mathrm{M})$ alone and control group $(P>0.05)$. ROS is a mediator of glucose toxicity in HT22 neuronal cells [27]. The intracellular ROS level was detected by measuring carboxy-H2DCFDA fluorescence. As shown in Figure 7D, HG treatment observably increased intracellular ROS level in HT22 cells compared with the control group $(P<0.01)$. Compared with the model group, incubation with NGR1 $(20 \mu \mathrm{M})$ obviously decreased intracellular ROS level $(P<0.01)$. These results showed that NGR1
A

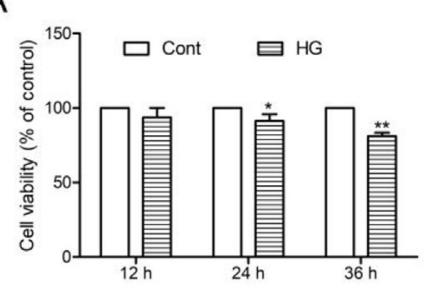

$\mathrm{D}$

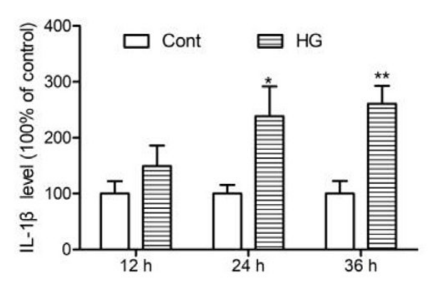

\section{B}

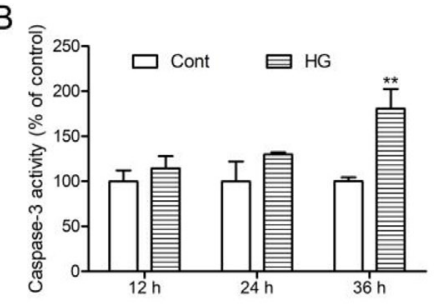

E

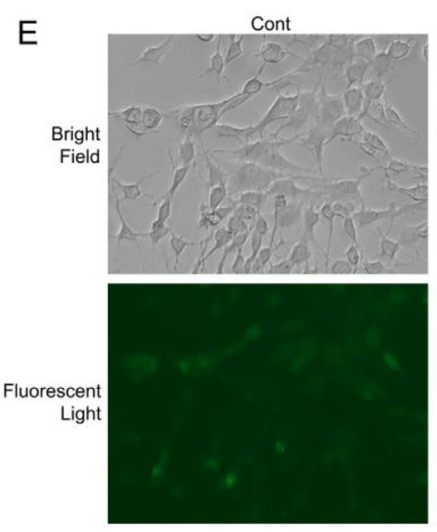

C
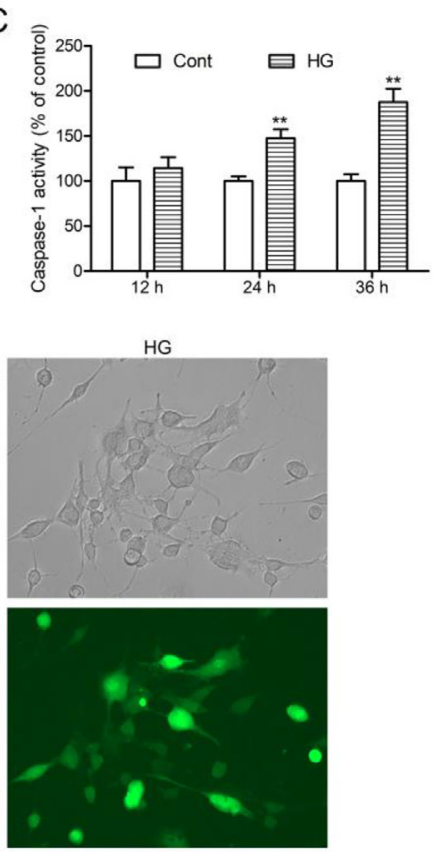

Figure 6: HG-induced injury, NLRP3 inflammasome activation and ROS production in HT22 hippocampal neurons. (A) Followed by incubation with $\mathrm{HG}(50 \mathrm{mM}$ vs control: $25 \mathrm{mM})$ at different time points $(12,24$ and $36 \mathrm{~h})$, and cell viability was detected by MTT assay. (B) Caspase-3 activity in HT22 hippocampal neurons after HG treatment at the indicated time periods. (C) Caspase-1 activity in HT22 hippocampal neurons after HG treatment at the indicated time periods. (D) IL-1 $\beta$ level in HT22 hippocampal neurons after $\mathrm{HG}$ treatment at the indicated time periods. (E) Intracellular ROS generation in HT22 hippocampal neurons after HG treatment for $36 \mathrm{~h}$ was visualised under a fluorescence microscopy. Values are represented as means $\pm \mathrm{SD}$ from three independent experiments. ${ }^{* *} P<0.01$, ${ }^{*} P<0.05$, compared with the control-group. 
treatment provides protection against HG-induced cell injury by inhibiting ROS production.

Intracellular oxidative stress was evaluated by measuring the content of lipid peroxidation product MDA, protein oxidation products protein carbonyl, and SOD activity. As shown in Figure 7F, 7G, and 7H, the SOD activity was observably decreased, whereas MDA, and protein carbonyl levels were observably decreased in $\mathrm{HG}$-treated cells compared with the control group $(P<0.01)$. Interestingly, NGR1 $(20 \mu \mathrm{M})$ treatment could enhance antioxidant enzyme SOD activity and lower MDA, protein carbonyl levels in HG-treated cells $(P<0.05)$. These results indicated that NGR1 can ameliorate HG-induced HT22 hippocampus neurons injury by inhibiting intracellular oxidative stress.

\section{NGR1 inhibits HG-induced NLRP3 inflammasome activation in HT22 hippocampal neurons}

Similar to previous studies, hyperglycemia caused NLRP3 inflammasome activation in HT22 hippocampal cells [14]. As shown in Figure 8A and 8B, NLRP3, ASC, and IL-1 $\beta$ expression levels and caspase- 1 activity in HT22 cells were significantly elevated in the HG group compared with the control group $(P<0.01)$. Moreover, NGR1 $(20 \mu \mathrm{M})$ treatment notably decreased NLRP3, ASC, and IL-1 $\beta$ expression levels and caspase- 1 activity in HT22 cells compared with the non-treated HG group $(P<0.01)$.

To explore the molecular mechanism of NGR1 treatment on the inhibition of oxidative stress and

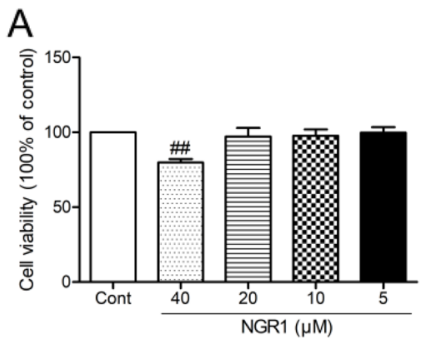

B

$\mathrm{D}$
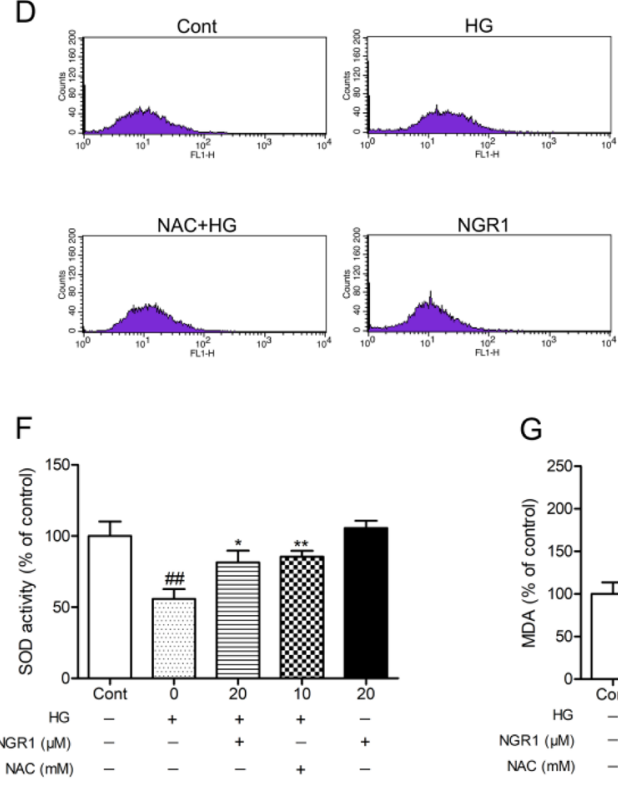
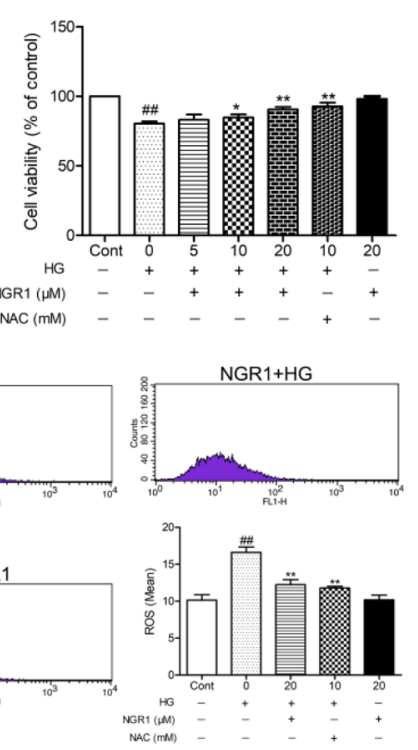

NGR1+HG

G

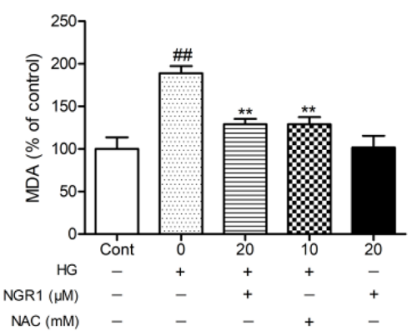

C

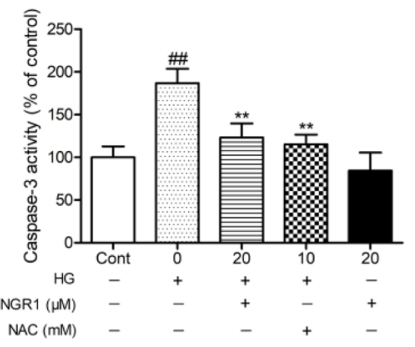

E

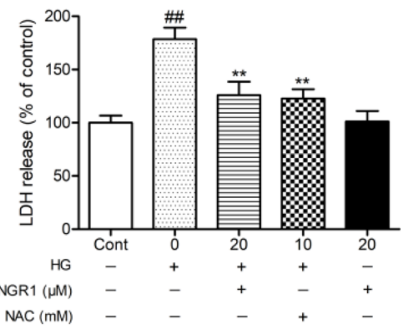

$\mathrm{H}$

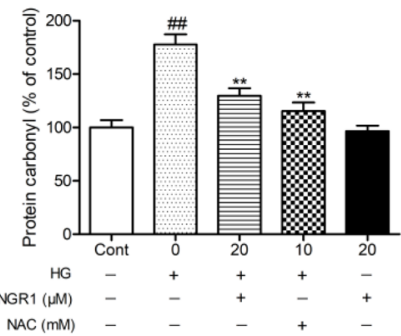

Figure 7: NGR1 ameliorates HG-induced cell injury, ROS production, and oxidative stress in HT22 hippocampal neurons. (A) NGR1 showed no obvious cytotoxicity on cell viability with concentrations under $20 \mu \mathrm{M}$. (B) Effects of NGR1 on HGinduced cell viability were measured by MTT assay. (C) Effects of NGR1 on HG-induced intracellular caspase-3 activity. (D) Effects of NGR1 on HG-induced intracellular ROS levels detected using a FACSCalibur Fow Cytometer. (E) Effects of NGR1 on HG-induced LDH release. (F) Intracellular SOD activity in HG-induced HT22 hippocampal neurons. (G) Intracellular MDA levels in HG-induced HT22 hippocampal neurons. (H) Intracellular protein carbonyl levels in HG-induced HT22 hippocampal neurons. Values are represented as means \pm SD from three independent experiments. ${ }^{\#} P<0.01$, compared with the control-group; ${ }^{* *} P<0.01,{ }^{*} P<0.05$, compared with the model-group. 
NLRP3 inflammasome activation, Akt, p-Akt, nuclear Nrf2, HO-1, and TXNIP expressions were detected using Western blot analysis. As shown in Figure 8C, after $36 \mathrm{~h}$ exposure to hyperglycemia, phosphorylated Akt, nuclear Nrf2, and HO-1 expression levels were significantly decreased, whereas TXNIP expression level was remarkably increased compared with the control group $(P<0.01)$. Moreover, treatment with NGR1 $(20 \mu \mathrm{M})$ obviously increased phosphorylated Akt, nuclear Nrf2, and HO-1 expression levels, while significantly decreased the TXNIP expression levels in the HT22 cells compared with the model group $(P$ $<0.05, P<0.01)$. Interestingly, a marked increase in phosphorylated Akt, unclear Nrf2, and HO-1 expression levels and a significant reduction in TXNIP expression levels were observed in HT22 cells treated with NGR1 alone $(P<0.05)$. These data indicated that NGR1 attenuates HG-induced injury in HT22 hippocampal neurons by activating the Akt/Nrf2/HO-1 pathway. Furthermore, NGR1 might promote the degradation of TXNIP by activating the PI3K/Akt pathway [19].

\section{PI3K inhibitor LY294002 abolishes the neuroprotective effects of NGR1 against HG- induced HT22 hippocampal neurons injury.}

To verify the effect of the Akt/Nrf2 pathway in the inhibition of oxidative stress and NLRP3 inflammasome activation in NGR1 treatment, the PI3K inhibitor LY294002 was used in experiments. As shown in Figure 9D, and 9E, the neuroprotective effect and inhibition of NLRP3 inflammasome activation of NGR1 were abolished by LY294002. Furthermore, LY294002 significantly decreased phosphorylated Akt, Nrf2 translocation, and HO-1 expression levels but TXNIP expression levels in HG- and NGR1-co-treated HT22 cells $(P<0.05)$ (Figure 9F). Most importantly, PI3K inhibitor LY294002 abolished the beneficial effect of NGR1 on the neuron injury in HG-induced HT22 cells (Figure 9A, 9B, and 9C). These results indicated that NGR1 exerts neuroprotective effects by activating the Akt/Nrf2/HO-1 pathway.
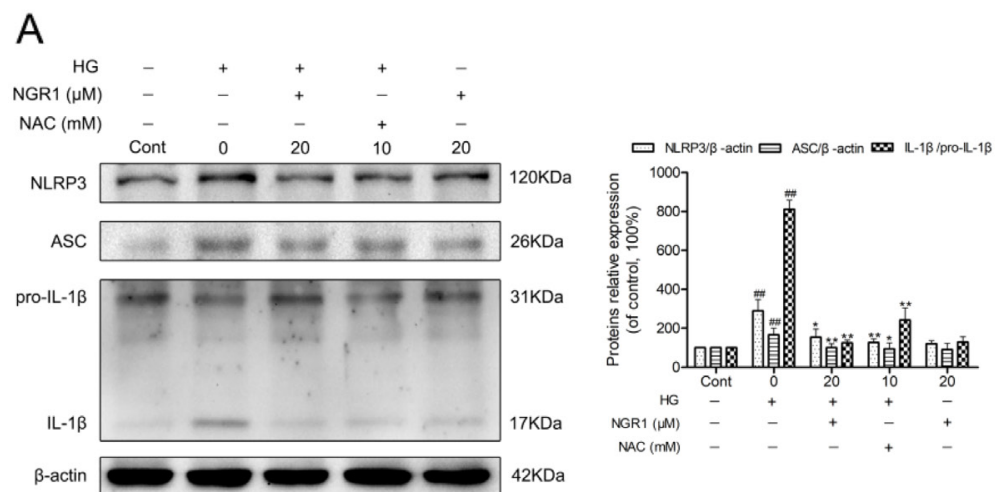

B
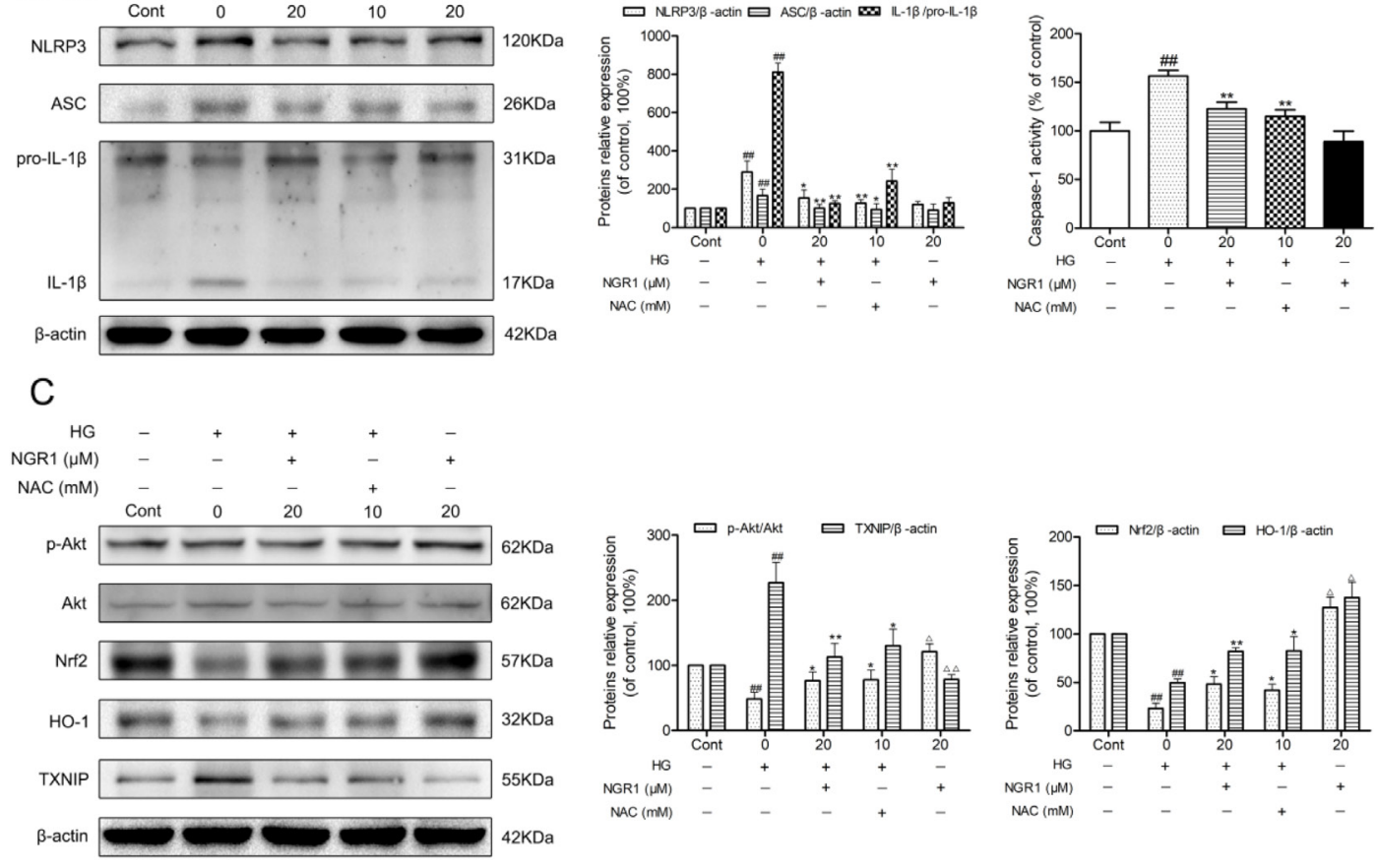

Figure 8: NGR1 activates the Akt/Nrf2/HO-1 pathway, and inhibits NLRP3 inflammasome activation in HG-induced HT22 hippocampal neurons. (A) Representative protein bands and Western blot analysis of NLRP3, ASC, and IL-1 $\beta$ in hippocampal neurons. (B) Caspase-1 activity in hippocampal neurons. (C) Representative protein bands and Western blot analysis of Akt, p-Akt, Nrf2, HO-1, and TXNIP in hippocampal neurons. Values are represented as means \pm SD from three independent experiments. ${ }^{\#} P<0.01, \Delta \Delta$ $P<0.01,{ }^{\Delta} P<0.05$ compared with the control-group; ${ }^{* *} P<0.01,{ }^{*} P<0.05$, compared with the model-group. 


\section{DISCUSSION}

In the present study, the diabetic $\mathrm{db} / \mathrm{db}$ mice exhibited the behavioral characteristics of cognition impairment and depression, accompanied with hyperglycemia, excessive body weight, hyperinsulinemia, dyslipidemia, insulin resistance, and peripheral and central inflammation. Administration of NGR1 for 10 weeks could alleviate cognition decline, depression behaviors, and insulin resistance in $\mathrm{db} / \mathrm{db}$ mice. And NGR1 treatment reduced peripheral inflammation and plasma TC, TG, LDL-C, and insulin levels in $\mathrm{db} / \mathrm{db}$ mice. In addition, we also found that neuronal oxidative stress and NLRP3 inflammasome activation were involved in the ameliorative effects of NGR1 against DEP in vivo and in vitro. NGR1 reduced $\mathrm{HG}$-induced oxidative stress by scavenging ROS, decreasing MDA, and oxidative carbonyl protein levels, increasing SOD activity and activating the Akt/Nrf2/HO-1 pathway. Moreover, our results identified that NGR1 is capable of decreasing TXNIP and NLRP3 inflammasome-related proteins expression both in vivo and in vitro. These findings suggested that inhibition of oxidative stress and NLRP3 inflammasome activation may be the vital mechanisms of NGR1 neuroprotection.

T2DM is a metabolic disease characterized by hyperglycemia, hyperinsulinemia, and dyslipidemia due

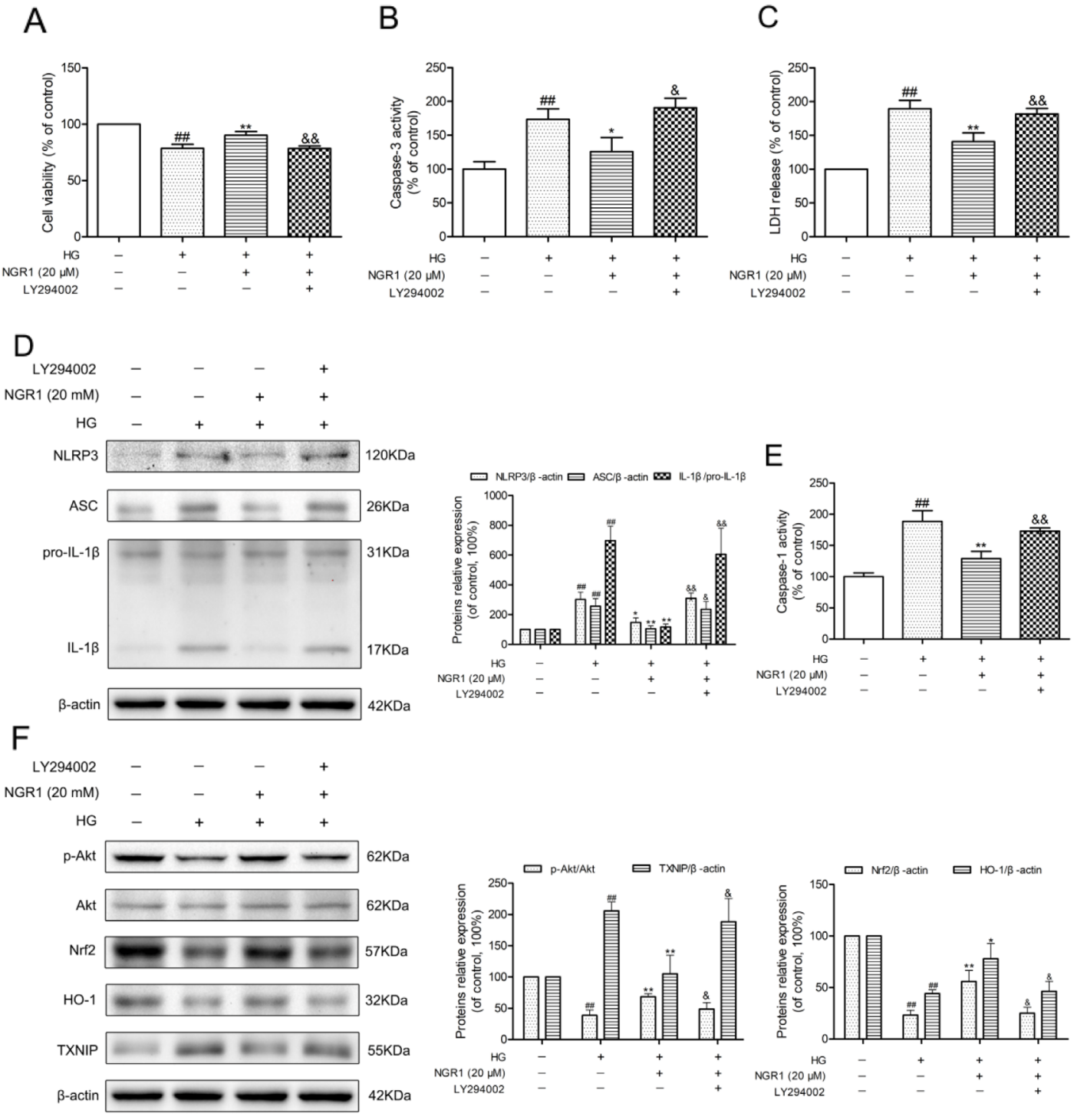

Figure 9: NGR1 exerts neuroprotective effects and inhibition of NLRP3 inflammasome by activating the Akt/Nrf2 pathway. (A) Cell viability was measured by MTT assay. (B) Caspase-3 activity in HT22 hippocampal neurons. (C) LDH release in HT22 hippocampal neurons. (D) Representative protein bands and Western blot analysis of NLRP3, ASC, and IL-1 $\beta$ in hippocampal neurons. (E) Caspase-1 activity in hippocampal neurons. (F) Representative protein bands and Western blot analysis of Akt, p-Akt, Nrf2, HO-1, and TXNIP in hippocampal neurons. Values are represented as means \pm SD from three independent experiments. ${ }^{\#} P<0.01$, compared with the control-group; ${ }^{* *} P<0.01,{ }^{*} P<0.05$, compared with the model-group; \&\& $P<0.01$, \& $P<0.05$, compared with the NGR1 (20 mM)-group. 
to insulin resistance. Disordered lipid metabolism and hyperinsulinemia lead to numerous neurological diseases $[33,34]$. Therefore, amelioration of hyperinsulinemia and dyslipidemia benefited the treatment of DEP. Similar to previous reports $[35,36], \mathrm{db} / \mathrm{db}$ mice exhibited high levels of TC, TG, LDL-C, and insulin in plasma. And administration of NGR1 for 10 weeks observably improved hyperinsulinemia and dyslipidemia in diabetic $\mathrm{db} / \mathrm{db}$ mice.

Inflammation plays an important role in the onset of TD2M and progression of its complications. Numerous evidences suggested that patients with TD2M are under a state of subclinical chronic inflammation [8]. Excessive inflammation in T2DM can disturb the blood-brain barrier permeability, which allows access of toxic substances to the brain, contributing to the pathophysiological processes of many neurodegenerative diseases [37]. It is well known that activated microglial cells are main source of inflammatory cytokines in central nervous system and CD11b protein is a marker of microglial cells [11]. Our study showed that hippocampal CD11b was increased, suggesting that neuroinflammation occurred in $\mathrm{db} / \mathrm{db}$ mice. Treatment with NGR1 could significantly decrease hippocampal CD11b expression in $\mathrm{db} / \mathrm{db}$ mice.
Moreover, administration of NGR1 could reduce IL$1 \beta$, IL-6, TNF- $\alpha$, and MCP-1 levels in plasma of $\mathrm{db} / \mathrm{db}$ mice. These data demonstrated that NGR1 ameliorates peripheral and central inflammation, which contributed to the improvement of DEP.

Researches in recent decades illuminated that IL$1 \beta$ accelerates the pathogenesis of neurodegenerative diseases and diabetic complications [9, 38]. Hippocampal IL-1 $\beta$ expression level is observably increased, and this increase is related to cognitive and emotional alterations in diabetic mice [28]. The cleavage and maturation of IL-1 $\beta$ are activated by NLRP3 inflammasome, and the activation of NLRP3 inflammasome can contribute to pathophysiological processes involved in diabetic complications and neurodegenerative diseases [13, 39]. The knockdown of NLRP3 or caspase-1 in APP/ PS1 mice can improve cognitive dysfunction [10]. Moreover, the inhibition of NLRP3 inflammasome activation can alleviate diabetic complications, including diabetic cardiomyopathy, diabetic nephropathy, diabetic retinopathy, diabetes-related wound-healing defects, and diabetic vascular endothelial dysfunction [40-44]. In the present study, high levels of IL-1 $\beta$ and NLRP3 inflammasome activation were observed in

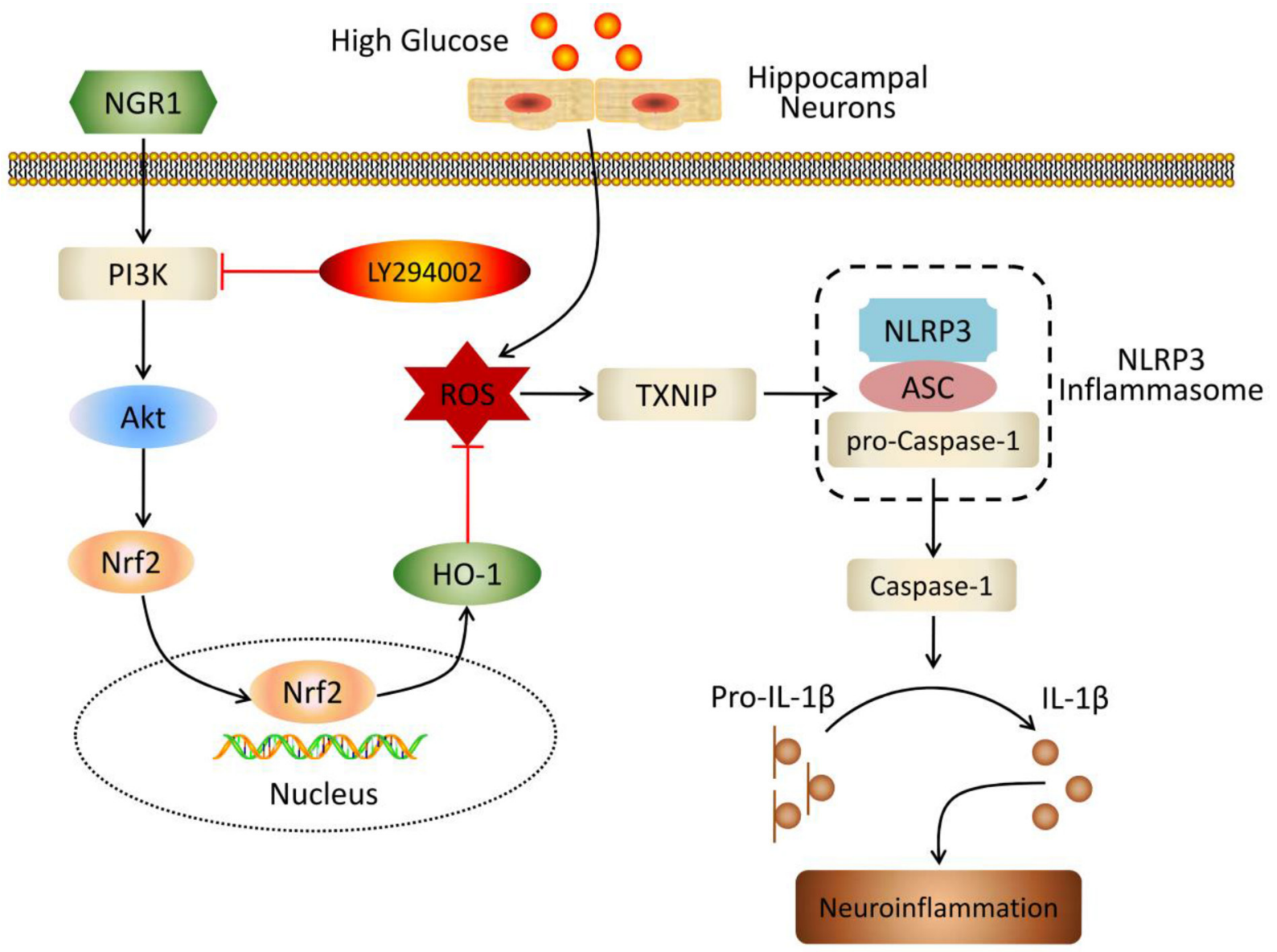

Figure 10: Schematic of NGR1 mechanism of ameliorating DEP by activating the Akt/Nrf2/HO-1 pathway and inhibiting NLRP3 inflammasome activation. 
the hippocampus of the $\mathrm{db} / \mathrm{db}$ mice and HG-induced hippocampal neurons, suggesting that hyperglycemia could activate NLRP3 inflammasome and induce hippocampal inflammation. Our data demonstrated that NGR1 could decrease NLRP3 inflammasome activation and IL-1 $\beta$ expression level in vivo and in vitro. Our results indicated that the inhibition of NLRP3 inflammasome is involved in the ameliorative effects of NGR1 against DEP.

The major upstream mechanisms of NLRP3 inflammasome activation include ROS, phagosomal destabilization, and ion fluxes [45]. Ample evidence showed that high rate of ROS is produced in hyperglycemia, thereby affecting neurons [27]. Our previous studies verified that NGR1 exerts neuroprotective and cardioprotective effects by inhibiting oxidative stress $[16,23]$. Therefore, we focused on the ability of NGR1 to reduce oxidative stress by detecting the levels of oxidative stress markers (ROS, MDA, protein carbonyls, and SOD). In the present study, high level of ROS generation was observed in HG treated HT22 cells. And incubation with NGR1 could significantly reduce ROS production. Furthermore, our data showed that NGR1 significantly increases SOD activity and reduces MDA, and protein carbonyl levels in the hippocampus of $\mathrm{db} / \mathrm{db}$ mice and HG-treated HT22 cells, which suggested its anti-oxidative efficiency.

TXNIP is a link between ROS and NLRP3 inflammasome activation [15]. ROS, a major upstream mechanism related to NLRP3 activation, induces the separation of TXNIP from thioredoxin and permits it to bind to NLRP3. TXNIP is a possible therapeutic target for diabetes and its related vascular complications [46]. In the present study, TXNIP expression level observably increased in the hippocampus of the diabetic mice and HGtreated HT22 cells. Moreover, treatment with NGR1 could remarkably decrease the expression of TXNIP in vivo and in vitro. Interestingly, there was a significant reduction in TXNIP expression level in HT22 cells incubated with NGR1 alone probably because of the activation of Akt phosphorylation [19].

$\mathrm{HO}-1$ is an endogenous anti-oxidant protein that is activated by Nrf2-dependent signaling pathway. Previous studies have indicated that activating the PI3K/Akt pathway induces the translocation of Nrf2 to the nucleus and increases HO-1 expression in hippocampal neurons [47]. In addition, activating the Nrf2/HO-1 pathway can decrease NLRP3 inflammasome activation [17, 48, 49]. In our previous studies, NGR1 exhibited neuroprotective effects by activating the Akt/Nrf2 pathway and increasing HO-1 expression [16]. In the present study, higher expression levels of phosphorylated Akt, Nrf2, and HO-1 were observed in the HT22 cells treated with NGR1 alone than in the control group, indicating that NGR1 intervention activates the Akt/Nrf2 pathway and promotes HO-1 expression. Our data also indicated that the Akt/ $\mathrm{Nrf} / \mathrm{HO}-1$ pathway is inactivated in the hippocampus of $\mathrm{db} / \mathrm{db}$ mice and HG-treated HT22 hippocampal neurons. NGR1 administration significantly increased the hippocampal phosphorylation of Akt, Nrf2, and HO-1 expression levels in vivo and in vitro. Interestingly, these changes were abolished by the PI3K inhibitor LY294002, thereby activating NLRP3 inflammasome and promoting TXNIP and IL-1 $\beta$ expression in hippocampal neurons. These results demonstrated that the neuroprotective properties of NGR1 were related to the up-regulation of the Akt/Nrf2/HO-1 pathway.

In summary, our work demonstrated that NGR1 treatment significantly ameliorated DEP, and NGR1 improved insulin resistance and dyslipidemia in $\mathrm{db} /$ $\mathrm{db}$ mice. Our results indicated that NGR1 elicited neuroprotective effects by activating the Akt/Nrf2/ HO-1 pathway, reducing oxidative stress, inhibiting NLRP3 inflammasome activation, and attenuating neuroinflammation (Figure 10). Therefore, these results showed that NGR1 may exhibit therapeutic properties for T2DM with DEP.

\section{MATERIALS AND METHODS}

\section{Reagents and antibodies}

Notoginsenoside R1 (NGR1, molecular weight = 933.14, CAS NO: 80418-24-2, purity>98.6) was obtained from Chengdu Must Biotechnology Co., Ltd (Chengdu, China). Dulbecco's modifed Eagle medium (DMEM), penicillin/streptomycin, and foetal bovine serum (FBS), and were supplied by Gibco (NewYork, USA). 0.25\% trypsin was purchased from Beijing Solarbio Science \& Technology Co., Ltd. (Beijing, China). The ELISA kit for determining the mouse insulin level was obtained from ALPCO (Salem, USA). The ELISA kit for determining the protein carbonyl was obtained from Cell Biolabs (San Diego, USA). The ELISA kits for detecting the mouse IL-6 and TNF- $\alpha$ were purchased from DAKEWEI (Shenzhen, China). The ELISA kit for determining the mouse MCP1 was obtained from Beijing Expandbiotech Co., Ltd. (Beijing, China). The ELISA kit for measuring IL-1 $\beta$ and reactive oxygen species assay kit, caspase-1 activity assay kit, caspase-3 activity assay kit, one step TUNEL apoptosis assay kit, proteinase K, 2-(4-Amidinophenyl)6-indolecarbamidine (DAPI) dihydrochloride staining solution, and $N$-acetyl-L-cysteine (NAC) were purchased from Beyotime Institute of Biotechnology (Beijing, China). Carboxymethylcellulose sodium was bought from Amresco (Houston, USA). The kits for determining the lactate dehydrogenase (LDH), malondialdehyde (MDA), and superoxide dismutase (SOD) were obtained from Nanjing jiancheng Bioengineering Institute (Nanjing, China). The commercial kits for detecting $\mathrm{TC}, \mathrm{TG}$, LDL-C, and HDL-C were obtained from Biosino Biotechnology \& Science Inc (Beijing, China). CarboxyH2DCFDA was offered from Life Technologies (Carlsbad, 
USA). Primary antibodies against NLRP3, CD11b, TXNIP, and HO-1 were obtained from abcam (Cambridge, UK). Primary antibodies against Akt, ASC, IL-1 $\beta$, and Nrf2 were purchased from Santa Cruz Biotechnology (Santa Cruz, CA, USA). Primary antibody against phospho-Akt (Ser473) was obtained from Cell Signaling Technology (Danvers, MA, USA). The peroxidaseconjugated secondary antibodies of goat anti-rabbit IgG and goat anti-mouse IgG were purchased from ZSJQBIO (Beijing, China). 3-(4,5-dimethylthiazol-2yl-)-2,5diphenyl tetrazolium bromide (MTT), PI3K inhibitor LY294002, and all of other regents were obtained from Sigma-Aldrich (St. Louis, USA).

\section{Animals}

Male 7-week old diabetic mice with a homozygous mutation of the leptin receptor (C57BLKS/J-lepr ${ }^{\mathrm{db}}$ / $\left.l \mathrm{pr}^{\mathrm{db}}\right)$ and age-matched non-diabetic mice $(\mathrm{db} / \mathrm{m})$ were supplied by the Model Animal Research Center of Nanjing University (Nanjing, China). The animals were placed under temperature- and humidity-controlled laboratory conditions (temperature: $22 \pm 2{ }^{\circ} \mathrm{C}$, humidity: $60 \pm 5 \%$ ). The mice were allowed free access to food and water, and were maintained under a $12 \mathrm{~h}$ light-dark cycle. All experimental procedures were approved by the Animal Ethics Committee of Peking Union Medical College.

\section{Experimental protocol}

After 1 week of adaption, the diabetic $\mathrm{db} / \mathrm{db}$ mice were randomly divided into three groups $(n=8$ each): model control group, NGR1 (30 mg/kg) group, and NGR1 (10 mg/kg) group. The non-diabetic $\mathrm{db} / \mathrm{m}$ mice were as control group $(n=8)$. The mice in control group and model group were administrated intragastrically with vehicle $(0.5 \%$ carboxymethyl cellulose solution). NGR1 treated groups were administrated intragastrically with $30 \mathrm{mg} / \mathrm{kg} /$ day or $10 \mathrm{mg} / \mathrm{kg} /$ day NGR1 in vehicle. Drug administration was performed once daily at around 9 a.m. All mice were treated for 10 weeks. Body weight and fasting blood glucose level were detected every week. Blood glucose level was detected after $6 \mathrm{~h}$ of fasting food with a portable glucometer (Roche Group, Switzerland).

\section{Oral glucose tolerance test and Insulin tolerance test}

Oral glucose tolerance test (OGTT) and insulin tolerance test (ITT) were performed as previous methods with slight modification [50]. After an overnight fast (12 h), OGTT or ITT were conducted by intragestrical administration of glucose solution ( $1 \mathrm{~g} / \mathrm{kg})$ or intraperitoneal injection of insulin $(0.75 \mathrm{U} / \mathrm{kg})$ in saline. Blood glucose level was detected at 0, 30, 60, 90, and 120 min after glucose administration or insulin injection, respectively.

\section{Behavioral tests}

Experiments were performed at 9 a.m.-17 p.m. under conditions of dim light and low noise.

\section{Tail suspension test (TST)}

The test was performed as described previously with slight modifications [5]. Each mouse was individually suspended by the tail to a vertical bar on the top of an opaque box $(30 \times 30 \times 30 \mathrm{~cm})$, with adhesive tape affixed $2 \mathrm{~cm}$ from the tip of the tail. A 6 min test was performed for each mouse. The immobility time was recorded for the last 4 min test. Immobility was set as the absence of any movements except those caused by respiration. The box was thoroughly cleaned using 75\% alcohol before each use to remove odor cues.

\section{Forced swim test (FST)}

The test was performed as previously described with little modifications [5]. Each mouse was placed into cylinder $(20 \mathrm{~cm}$ height $\times 13 \mathrm{~cm}$ diameters $)$ containing $25{ }^{\circ} \mathrm{C}$ water $15 \mathrm{~cm}$ deep so that the mouse could not support itself by contacting the bottom. A 6-min test for each mouse was videotaped by a camera placed above the cylinder. The immobility time was measured for the last 4 min. Immobility was defined as the absence of necessary movements except those required for respiration. The water temperature was controlled at $25^{\circ} \mathrm{C}$.

\section{Morris water maze test}

The MWM test was performed according to the method described previously with minor modifications to assess spatial memory [51]. The test included a 5-day training (visible- and hidden- platform training sessions) and a probe trial on day 6 . The water maze equipment included a circular pool (100 cm in diameter, $50 \mathrm{~cm}$ in height), a black platform ( $9 \mathrm{~cm}$ in diameter), and a computer equipped with a management system (Super Maze, Shanghai Xinruan Information Technology Co., Ltd. China). The mouse was trained in the pool filled up with water maintained at 25 $\pm 1{ }^{\circ} \mathrm{C}$. The maze was located in a lit room with visual cues. The pool was spatially divided into four imaginary quadrants and the platform was placed in the center of one quadrant. The position of the platform was invariant during the visible-platform and hidden-platform training sessions. The visible-platform training was implemented to detect differences in the vision and motivation of each group. The platform was placed $1 \mathrm{~cm}$ below the water surface and marked with a small flag ( $5 \mathrm{~cm}$ in height) in the visible-platform training. The hidden-platform training was facilitated to evaluate the ability of spatial learning. The flag was removed and the platform was placed $1 \mathrm{~cm}$ underneath the water surface. For each trial per day, each mouse was performed to four trials with a $1 \mathrm{~h}$ interval. Escape latency 
data were recorded. The training trial began with placing the animal in the water facing the wall of the pool and drop location was randomly changed for each trial. Each trial lasted until the mouse reached the platform and stayed there for $10 \mathrm{~s}$. If the mouse failed to find the platform within $90 \mathrm{~s}$, the trial was ended and the mouse was guided to the platform for $30 \mathrm{~s}$; its escape latency was recorded as $90 \mathrm{~s}$. On day 6, the probe trial began. Each mouse was allowed to swim freely in the pool for $90 \mathrm{~s}$ without the platform. The time spent in the target quadrant and the numbers of mice crossing through the original platform position were recorded.

\section{Preparation of tissue samples}

After completion of the behavioral tests, overnight fasted mice were anesthetized by isoflurane inhalation. Blood samples were collected by cardiac puncture into EDTA (10\%)-coated chilled tubes. After centrifugation (10 min, $3000 \mathrm{~g}, 4{ }^{\circ} \mathrm{C}$ ), plasma were stored at $-80{ }^{\circ} \mathrm{C}$ for further measurement. Three mice from each group were transcardially perfused with PBS followed by a $4 \%$ paraformaldehyde fixative solution. Brains were gently removed, immersed for $24 \mathrm{~h}$ in fixative, and then processed for subsequent experiment. The remaining mice of each group were perfused with cold PBS through the ascending aorta. Mice were decapitated and prefrontal cortex and the hippocampus were rapidly and carefully dissected on ice plate. The tissues were immediately collected into labeled-sterile tubes and frozen in liquid nitrogen and then stored at $-80{ }^{\circ} \mathrm{C}$ until assays.

The plasma from each mouse were used to detect cytokines (L-1 $\beta$, IL- 6 , TNF- $\alpha$, and MCP-1), insulin, and lipids (TC, TG, LDL-C, and HDL-C). Three brains in $4 \%$ paraformaldehyde fixative solution from each group were used for H\&E, Nissl's, and TUNEL staining. The remaining hippocampal tissues were used for biochemical detection and western blotting.

\section{Measurement of plasma cytokines, lipids, and insulin}

The levels of plasma cytokines (IL- $1 \beta$, IL-6, TNF- $\alpha$, and MCP-1) and insulin were measured by enzymelinked immune sorbent assay (ELISA) kits following the manufacturer's instructions as previously described. The levels of TC, TG, LDL-C, and HDL-C were detected by a Hitachi7600 Automatic Biochemistry Analyzer (Tokyo, Japan) according to the manufacturer's instructions.

\section{Measurement of caspase-1, caspase-3, SOD, MDA, and protein carbonyl}

The activities of caspase-1, caspase-3, and SOD and contents of MDA, and protein carbonyl were detected by the kits following the manufacturer's instructions.

\section{H\&E and Nissl's staining}

The fixed brains were embedded in paraffin and coronally dissected into $5 \mu \mathrm{m}$ thick sections. In order to assess the damage of hippocampus, the brain paraffin sections were processed as described previously for histopathological examination by H\&E staining [7]. The brain paraffin sections were also conducted by the method as described previously for Nissl's staining. Images were analyzed by using a light microscope $\left(\right.$ EVOS $^{\circledR}$ XL Core, Life Technologies).

\section{Terminal deoxynucleotidyl transferase-mediated dUTP-biotin nick end labeling (TUNEL) assay}

Cell apoptosis was assessed by a one step TUNEL apoptosis assay kit according to the previously described method [52]. In brief, brain paraffin sections were dewaxed and rehydrated, and then incubated in proteinase $\mathrm{K}$ working solution at $25^{\circ} \mathrm{C}$ for 30 minutes. After being washed in PBS, sections were treated with TUNEL reaction mixture for $1 \mathrm{~h}$ at $37^{\circ} \mathrm{C}$ in dark. And then, sections were incubated with DAPI solution for 3 minutes. Images were captured using a fluorescence microscope (EVOS ${ }^{\circledR}$ FL Color, Life Technologies).

\section{Western blot analysis}

Western blot was performed as previous report [53]. The tissues of hippocampus were weighed and homogenized in lysis buffer (1: 100 inhibitor proteases and phosphatases cocktail). In contrast to hippocampal tissues, the HT22 cells were lysed in sample buffer and sonicated by an ultrasonic cell disrupter. Total protein was determined by bicinchoninic acid (BCA) kits. The primary antibodies NLRP3 (1:1000), ASC (1:200), IL-1 $\beta$ (1:200), TXNIP (1:1000), Akt (1:200), p-Akt (1:1000), CD11b (1:1000), Nrf2 (1:200), HO-1 (1:1000) and $\beta$-actin (1:1000) were used for blotting. The proteins were visualized using a super enhanced chemiluminescence reagent. Western blotting images were analyzed using Image Lab software (BIO-RAD, USA).

\section{Cell culture and treatment}

The HT22 cell (mouse hippocampal neuronal cell line), which has served as a successful extracorporeal model in the study of diabetes associated hippocampal damage, were obtained from Beijing Beina Chuanglian Biotechnology Institute (Beijing, China). The cells were cultured in high glucose DMEM medium $(25 \mathrm{mM}$ glucose) containing $10 \% \mathrm{FBS}, 100 \mathrm{U} / \mathrm{ml}$ penicillin, and $100 \mathrm{mg} / \mathrm{ml}$ streptomycin at $37^{\circ} \mathrm{C}$ with $5 \% \mathrm{CO}_{2}$ [26]. After reaching $80 \%$ confluency, the cells were trypsinized and processed for subsequent experiment. Cells treated with different concentrations of NGR1, were incubated with HG (DMEM containing additional $25 \mathrm{mM}$ glucose, total 
$50 \mathrm{mM}$ glucose; HG group) for 12, 24, 36 hours. Control group did not add any additional glucose (total $25 \mathrm{mM}$ glucose; control group).

\section{Detection for cell viability and $\mathrm{LDH}$ release}

The cell viability of HT22 cells was evaluated by MTT assay [26]. Cells were seeded in 96-well cell culture plate at the seeding density of $4 \times 10^{3} /$ well for $24 \mathrm{~h}$. After incubation with glucose or drugs, culture medium was replaced with MTT medium, and further incubated at $37^{\circ} \mathrm{C}$ for $4 \mathrm{~h} .150 \mu \mathrm{l}$ of DMSO was added to each well with shaking $10 \mathrm{~min}$, before reading the plate. The optical density (OD) value was detected by a microplate reader (Infinite M1000, Tecan Sunrise, Austria) at wavelength of $570 \mathrm{~nm}$. The relative cell viability (\%) was calculated by the following formula: (OD value of experimental group) $/$ (OD value of control group) $\times 100 \%$.

Cell death was evaluated by LDH release. The medium of the HT22 hippocampus neurons was collected to detect LDH release by kit. Data were presented as relative levels of the control group.

\section{Measurement of intracellular ROS production by fluorescence microscopy and flow cytometry}

The intracellular ROS production was monitored using a fluorescent probe DCFH-DA. After treatment, cells were incubated with $10 \mu \mathrm{M}$ DCFH-DA for 25 min at $37{ }^{\circ} \mathrm{C}$ and then washed thrice with phosphatebuffered saline (PBS) buffer. Finally, cellular morphology and fluorescence distributions were observed using a fluorescence microscopy $\left(\right.$ EVOS $^{\circledR}$ FL Color, Life Technologies).

After treatment, cells were harvested by $0.25 \%$ trypsin and washed by PBS buffer. And then cells were centrifuged and incubated with 5-(and-6)-carboxy-2', 7'-dichlorodihydrofluorescein diacetate (carboxyH2DCFDA) in the dark at $37{ }^{\circ} \mathrm{C}$ for $30 \mathrm{~min}$. The fluorescence was analyzed by a flow cytometry (BD, Biosciences, CA, USA).

\section{Statistical analysis}

All data were expressed as means \pm standard deviation (SD). The results were analyzed by a one way analysis of variance (ANOVA) based on Student's twotailed unpaired $t$-test. The $P$ values less than 0.05 were considered to be statistically significant.

\section{Abbreviations}

$\mathrm{AD}$, Alzheimer's disease; ANOVA, a one way analysis of variance; BCA, bicinchoninic acid; CNS, central nervous system; DAPI, 2-(4-Amidinophenyl)6-indolecarbamidine; DEP, diabetic encephalopathy; DM, diabetes mellitus; DMEM, Dulbecco's modifed
Eagle medium; FBS, foetal bovine serum; FST, forced swim test; HG, high glucose; HDL-C, high-density lipoprotein cholesterol; HO-1, Heme oxygenase-1; IL-1 $\beta$, Interleukine-1 $\beta$; IL-6, Interleukine-6; ITT, insulin tolerance test; $\mathrm{LDH}$, lactate dehydrogenase; LDL-C, low-density lipoprotein cholesterol; MAPK, mitogen-activated protein kinase; MCP-1, monocyte chemoattractant protein-1; MDA, malondialdehyde; MWM, Morris water maze; MTT, 3-(4,5-dimethylthiazol2yl-)-2,5-diphenyl tetrazolium bromide; NAC, $N$-acetylL-cysteine; NGR1, Notoginsenoside R1; Nrf2, nuclear factor-erythroid 2-related factor2; OD, optical density; OGTT, oral glucose tolerance test; PI3K, phosphatidyl inositol 3-kinase; ROS, reactive oxygen species; SD, standard deviation; SOD, superoxide dismutase; TC, total cholesterol; T2DM, type 2 diabetes mellitus; TG, triglyceride; TNF- $\alpha$, tumor necrosis factor- $\alpha$; TST, tail suspension test; TUNEL, Terminal deoxynucleotidyl transferase-mediated dUTP-biotin nick end labeling; TXNIP, thioredoxin-interacting protein;

\section{Author contributions}

Designed and performed the experiments: Yadong Zhai, Xiangbao Meng, Guibo Sun, and Xiaobo Sun. Collected samples and analysed the data: Yadong Zhai, Lili Zhu, Yongmei Wu, Tianyuan Ye, Min Wang, and Ping Zhou. Prepared the figures: Yadong Zhai, Xiangbao Meng, and Yun Luo. Supervised the experiments and revised the manuscript: Guibo Sun, and Xiaobo Sun. Wrote the paper: Yadong Zhai, and Xiangbao Meng.

\section{CONFLICTS OF INTEREST}

There is no conflicts of interest.

\section{FUNDING}

This work was supported by the Major Scientific and Technological Special Project for "Significant New Drugs Formulation" (No. 2017ZX09101003-009), the Chinese Academy of Medical Sciences (CAMS) Innovation Fund for Medical Sciences (No. 2016-I2M-1-012), the CAMS Initiative for Innovative Medicine (No. CAMSI2M-1-010), the Special Research Project for TCM (No. 201507004), the National Natural Science Foundation of China (No. 81503290), and the Fundamental Research Funds for the Central Universities and the Peking Union Medical College Youth Found (No. 3332016076).

\section{REFERENCES}

1. Cukierman T, Gerstein HC, Williamson JD. Cognitive decline and dementia in diabetes--systematic overview of prospective observational studies. Diabetologia. 2005; 48:2460-2469. 
2. Arvanitakis Z, Wilson RS, Bienias JL, Evans DA, Bennett DA. Diabetes mellitus and risk of Alzheimer disease and decline in cognitive function. Arch Neurol. 2004; 61:661-666.

3. McCrimmon RJ, Ryan CM, Frier BM. Diabetes and cognitive dysfunction. Lancet. 2012; 379:2291-2299.

4. de Cossio LF, Fourrier C, Sauvant J, Everard A, Capuron L, Cani PD, Laye S, Castanon N. Impact of prebiotics on metabolic and behavioral alterations in a mouse model of metabolic syndrome. Brain Behav Immun. 2017; 64:33-49.

5. Liu W, Liu J, Xia J, Xue X, Wang H, Qi Z, Ji L. Leptin receptor knockout-induced depression-like behaviors and attenuated antidepressant effects of exercise are associated with STAT3/SOCS3 signaling. Brain Behav Immun. 2017; 61:297-305.

6. Yasin Wayhs CA, Tannhauser Barros HM, Vargas CR. GABAergic modulation in diabetic encephalopathy-related depression. Curr Pharm Des. 2015; 21:4980-4988.

7. Wang ZG, Huang Y, Cheng Y, Tan Y, Wu FZ, Wu JM, Shi HX, Zhang HY, Yu XC, Gao HC, Lin L, Cai J, Zhang JS, et al. Endoplasmic reticulum stress-induced neuronal inflammatory response and apoptosis likely plays a key role in the development of diabetic encephalopathy. Oncotarget. 2016; 7:78455-78472. https://doi.org/10.18632/ oncotarget.12925.

8. Seto SW, Yang GY, Kiat H, Bensoussan A, Kwan YW, Chang D. Diabetes mellitus, cognitive impairment, and traditional chinese medicine. Int $\mathrm{J}$ Endocrinol. 2015; 2015:810439.

9. Pan Y, Chen XY, Zhang QY, Kong LD. Microglial NLRP3 inflammasome activation mediates IL-1 $\beta$-related inflammation in prefrontal cortex of depressive rats. Brain Behav Immun. 2014; 41:90-100.

10. Heneka MT, Kummer MP, Stutz A, Delekate A, Schwartz S, Vieira-Saecker A, Griep A, Axt D, Remus A, Tzeng TC, Gelpi E, Halle A, Korte M, et al. NLRP3 is activated in Alzheimer's disease and contributes to pathology in APP/PS1 mice. Nature. 2013; 493:674-678.

11. Xu Y, Sheng H, Bao Q, Wang Y, Lu J, Ni X. NLRP3 inflammasome activation mediates estrogen deficiencyinduced depression- and anxiety-like behavior and hippocampal inflammation in mice. Brain Behav Immun. 2016; 56:175-186.

12. Zhang Y, Liu L, Liu YZ, Shen XL, Wu TY, Zhang T, Wang W, Wang YX, Jiang CL. NLRP3 inflammasome mediates chronic mild stress-induced depression in mice via neuroinflammation. Int J Neuropsychopharmacol. 2015; 18:1-8.

13. Volpe CM, Anjos PM, Nogueira-Machado JA. Inflammasome as a new therapeutic target for diabetic complications. Recent Pat Endocr Metab Immune Drug Discov. 2016; 10:56-62.
14. Ward R, Ergul A. Relationship of endothelin-1 and NLRP3 inflammasome activation in HT22 hippocampal cells in diabetes. Life Sci. 2016; 159:97-103.

15. Zhou R, Tardivel A, Thorens B, Choi I, Tschopp J. Thioredoxin-interacting protein links oxidative stress to inflammasome activation. Nat Immunol. 2010; 11:136-140.

16. Meng X, Wang M, Wang X, Sun G, Ye J, Xu H, Sun X. Suppression of NADPH oxidase- and mitochondrionderived superoxide by notoginsenoside R1 protects against cerebral ischemia-reperfusion injury through estrogen receptor-dependent activation of AKT/NRF2 pathways. Free Radic Res. 2014; 48:823-838.

17. Cai M, Wang H, Li JJ, Zhang YL, Xin L, Li F, Lou SJ. The signaling mechanisms of hippocampal endoplasmic reticulum stress affecting neuronal plasticity-related protein levels in high fat diet-induced obese rats and the regulation of aerobic exercise. Brain Behav Immun. 2016; 57:347-359.

18. Luo Y, Sun GB, Dong X, Wang M, Qin M, Yu Y, Sun $\mathrm{XB}$. Isorhamnetin attenuates atherosclerosis by inhibiting macrophage apoptosis via PI3K/AKT activation and HO-1 induction. PLoS One. 2015; 10:e120259.

19. Zaragoza-Campillo MA, Moran J. Reactive oxygen species evoked by potassium deprivation and staurosporine inactivate Akt and induce the expression of TXNIP in cerebellar granule neurons. Oxid Med Cell Longev. 2017; 2017:8930406.

20. Liao DY, Qu ZQ, Zhong ZG, Qin ZL, Xi JY, Tan C, Lin $\mathrm{SN}$, Zhu YP. Research on protective function of panax notoginseng saponins for spatial cognitive functions and hippocampal neurons in diabetic mice. J Tradit Chin Med. 2014; 37:466-470.

21. Sun B, Xiao J, Sun XB, Wu Y. Notoginsenoside R1 attenuates cardiac dysfunction in endotoxemic mice: an insight into oestrogen receptor activation and PI3K/Akt signalling. Br J Pharmacol. 2013; 168:1758-1770.

22. Ma B, Meng X, Wang J, Sun J, Ren X, Qin M, Sun J, Sun G, Sun $X$. Notoginsenoside R1 attenuates amyloid- $\beta$-induced damage in neurons by inhibiting reactive oxygen species and modulating MAPK activation. Int Immunopharmacol. 2014; 22:151-159.

23. Yu Y, Sun G, Luo Y, Wang M, Chen R, Zhang J, Ai Q, Xing N, Sun X. Cardioprotective effects of notoginsenoside $\mathrm{R} 1$ against ischemia/reperfusion injuries by regulating oxidative stress- and endoplasmic reticulum stress- related signaling pathways. Sci Rep. 2016; 6:21730.

24. Yan S, Li Z, Li H, Arancio O, Zhang W. Notoginsenoside R1 increases neuronal excitability and ameliorates synaptic and memory dysfunction following amyloid elevation. Sci Rep. 2014; 4:6352.

25. Huang G, Lv J, Li T, Huai G, Li X, Xiang S, Wang L, Qin Z, Pang J, Zou B, Wang Y. Notoginsenoside R1 ameliorates podocyte injury in rats with diabetic nephropathy by 
activating the PI3K/Akt signaling pathway. Int J Mol Med. 2016; 38:1179-1189.

26. Fan $F$, Liu $T$, Wang $X$, Ren $D$, Liu $H$, Zhang $P$, Wang Z, Liu N, Li Q, Tu Y, Fu J. CLC-3 expression and its association with hyperglycemia induced HT22 hippocampal neuronal cell apoptosis. J Diabetes Res. 2016; 2016:2984380.

27. Rackova L, Snirc V, Jung T, Stefek M, Karasu C, Grune T. Metabolism-induced oxidative stress is a mediator of glucose toxicity in HT22 neuronal cells. Free Radic Res. 2009; 43:876-886.

28. Dinel AL, André C, Aubert A, Ferreira G, Layé S, Castanon N. Cognitive and emotional alterations are related to hippocampal inflammation in a mouse model of metabolic syndrome. PLoS One. 2011; 6:e24325.

29. Sharma AN, Elased KM, Garrett TL, Lucot JB. Neurobehavioral deficits in $\mathrm{db} / \mathrm{db}$ diabetic mice. Physiol Behav. 2010; 101:381-388.

30. Habib P, Beyer C. Regulation of brain microglia by female gonadal steroids. J Steroid Biochem Mol Biol. 2015; 146:3-14.

31. Li XH, Xin X, Wang Y, Wu JZ, Jin ZD, Ma LN, Nie CJ, Xiao X, Hu Y, Jin MW. Pentamethylquercetin protects against diabetes-related cognitive deficits in diabetic gotokakizaki rats. J Alzheimers Dis. 2013; 34:755-767.

32. Liu D, Zhang H, Gu W, Liu Y, Zhang M. Neuroprotective effects of ginsenoside Rb1 on high glucose-induced neurotoxicity in primary cultured rat hippocampal neurons. PloS One. 2013; 8:e79399.

33. Ellis JM, Wong GW, Wolfgang MJ. Acyl coenzyme A thioesterase 7 regulates neuronal fatty acid metabolism to prevent neurotoxicity. Mol Cell Biol. 2013; 33:1869-1882.

34. Luchsinger JA, Tang MX, Shea S, Mayeux R. Hyperinsulinemia and risk of Alzheimer disease. Neurology. 2004; 63:1187-1192.

35. Cao AL, Wang L, Chen X, Wang YM, Guo HJ, Chu S, Liu C, Zhang XM, Peng W. Ursodeoxycholic acid and 4-phenylbutyrate prevent endoplasmic reticulum stressinduced podocyte apoptosis in diabetic nephropathy. Lab Invest. 2016; 96:610-622.

36. Yoon JJ, Lee YJ, Kang DG, Lee HS. Protective role of oryeongsan against renal inflammation and glomerulosclerosis in db/db mice. Am J Chin Med. 2014; 42:1431-1452.

37. Bell RD, Zlokovic BV. Neurovascular mechanisms and blood-brain barrier disorder in Alzheimer's disease. Acta Neuropathol. 2009; 118:103-113.

38. Peiro C, Lorenzo O, Carraro R, Sanchez-Ferrer CF. IL-1 $\beta$ inhibition in cardiovascular complications associated to diabetes mellitus. Front Pharmacol. 2017; 8:363.

39. Shao QH, Zhang XL, Yang PF, Yuan YH, Chen NH. Amyloidogenic proteins associated with neurodegenerative diseases activate the NLRP3 inflammasome. Int Immunopharmacol. 2017; 49:155-160.
40. Bauer PM, Luo B, Li B, Wang W, Liu X, Xia Y, Zhang C, Zhang M, Zhang Y, An F. NLRP3 gene silencing ameliorates diabetic cardiomyopathy in a type 2 diabetes rat model. PLoS One. 2014; 9:e104771.

41. Bitto A, Altavilla D, Pizzino G, Irrera N, Pallio G, Colonna MR, Squadrito F. Inhibition of inflammasome activation improves the impaired pattern of healing in genetically diabetic mice. Br J Pharmacol. 2014; 171:2300-2307.

42. Zhang J, Xia L, Zhang F, Zhu D, Xin C, Wang H, Zhang F, Guo X, Lee Y, Zhang L, Wang S, Guo X, Huang C, et al. A novel mechanism of diabetic vascular endothelial dysfunction: Hypoadiponectinemia-induced NLRP3 inflammasome activation. Biochim Biophys Acta. 2017; 1863:1556-1567.

43. Wang S, Li Y, Fan J, Zhang X, Luan J, Bian Q, Ding T, Wang Y, Wang Z, Song P, Cui D, Mei X, Ju D. Interleukin-22 ameliorated renal injury and fibrosis in diabetic nephropathy through inhibition of NLRP3 inflammasome activation. Cell Death Dis. 2017; 8:e2937.

44. Devi TS, Lee I, Huttemann M, Kumar A, Nantwi KD, Singh LP. TXNIP links innate host defense mechanisms to oxidative stress and inflammation in retinal muller glia under chronic hyperglycemia: implications for diabetic retinopathy. Exp Diabetes Res. 2012; 2012:438238.

45. Lan Z, Xie G, Wei M, Wang P, Chen L. The protective effect of Epimedii Folium and Curculiginis Rhizoma on Alzheimer's Disease by the inhibitions of NF- $\kappa \mathrm{B} / \mathrm{MAPK}$ pathway and NLRP3 inflammasome. Oncotarget. 2017; 8:43709-43720. https://doi.org/10.18632/oncotarget.12574.

46. $\mathrm{Wu} \mathrm{P}, \mathrm{Du} \mathrm{GH}$. Thioredoxin-interacting protein: a new potential target for diabetes and related vascular complications therapy. Acta Pharmaceutica Sinica. 2015; 50:1559-1564.

47. Lee DS, Jeong GS. Butein provides neuroprotective and anti-neuroinflammatory effects through Nrf2/AREdependent haem oxygenase 1 expression by activating the PI3K/Akt pathway. Br J Pharmacol. 2016; 173:2894-2909.

48. Hou Y, Wang Y, He Q, Li L, Xie H, Zhao Y, Zhao J. Nrf2 inhibits NLRP3 inflammasome activation through regulating Trx1/TXNIP complex in cerebral ischemia reperfusion injury. Behav Brain Res. 2017; 336:32-39.

49. Liu X, Wang T, Liu X, Cai L, Qi J, Zhang P, Li Y. Biochanin A protects lipopolysaccharide/D-galactosamine-induced acute liver injury in mice by activating the Nrf2 pathway and inhibiting NLRP3 inflammasome activation. Int Immunopharmacol. 2016; 38:324-331.

50. Gu C, Zhou W, Wang W, Xiang H, Xu H, Liang L, Sui $\mathrm{H}$, Zhan L, Lu X. ZiBuPiYin recipe improves cognitive decline by regulating gut microbiota in Zucker diabetic fatty rats. Oncotarget. 2017; 8:27693-27703. https://doi. org/10.18632/oncotarget.14611.

51. Chen F, Dong RR, Zhong KL, Ghosh A, Tang SS, Long Y, Hu M, Miao MX, Liao JM, Sun HB, Kong LY, Hong H. Antidiabetic drugs restore abnormal transport of 
amyloid-beta across the blood-brain barrier and memory impairment in $\mathrm{db} / \mathrm{db}$ mice. Neuropharmacology. 2016; 101:123-136.

52. Zhang SJ, Xu TT, Li L, Xu YM, Qu ZL, Wang XC, Huang SQ, Luo Y, Luo NC, Lu P, Shi YF, Yang X, Wang Q. Bushen-Yizhi formula ameliorates cognitive dysfunction through SIRT1/ER stress pathway in SAMP8 mice. Oncotarget. 2017; 8:49338-49350. https://doi.org/10.18632/ oncotarget. 17638 .
53. Peng S, Gao J, Liu W, Jiang CH, Yang XL, Sun Y, Guo WJ, Xu Q. Andrographolide ameliorates OVA-induced lung injury in mice by suppressing ROS-mediated $\mathrm{NF}-\kappa \mathrm{B}$ signaling and NLRP3 inflammasome activation. Oncotarget. 2016; 7:80262-80274. https://doi.org/10.18632/ oncotarget.12918. 